\title{
Review
}

\section{Dancing with Azulene}

\author{
Alexandru C. Razus
}

check for

updates

Citation: Razus, A.C. Dancing with

Azulene. Symmetry 2022, 14, 297.

https://doi.org/10.3390/

sym 14020297

Academic Editor: György Keglevich

Received: 22 December 2021

Accepted: 22 January 2022

Published: 1 February 2022

Publisher's Note: MDPI stays neutral with regard to jurisdictional claims in published maps and institutional affiliations.

Copyright: (C) 2022 by the author. Licensee MDPI, Basel, Switzerland. This article is an open access article distributed under the terms and conditions of the Creative Commons Attribution (CC BY) license (https:/ / creativecommons.org/licenses/by/ $4.0 /)$.
“C.D. Nenitzescu” Institute of Organic Chemistry, Romanian Academy, 202 B Spl. Independentei, P.O. Box 35-108, 060023 Bucharest, Romania; acrazus@yahoo.com

\begin{abstract}
It seems interesting to adopt the idea of dance in the context of the arrangement of molecular blocks in the building of molecular systems. Just as various dances can create various feelings, the nature and arrangement of molecular blocks in the generated molecular system can induce different properties. We consider obtaining such "dancing" systems in which the still little-known azulene moieties are involved. The dark blue nonbenzenoid aromatic azulene has one less axis of symmetry relative to the two axes of its isomer, i.e., the fully benzenoid naphthalene, acquiring valuable properties as a result that can be used successfully in technical applications. In a dancing system, the azulene moieties can be connected directly, or a more or less complex spacer can be inserted between them. Several azulene moieties can form a linear oligomer or a polymer and the involvement of azulene moieties in nonlinear molecules, such as crown ethers, calixarenes, azuliporphyrins, or azulenophane, is a relatively new and intensely studied topic. Some aspects are covered in this review, which are mainly related to obtaining the mentioned azulene compounds and less to their characterization or physico-chemical properties.
\end{abstract}

Keywords: azulene; linear and nonlinear oligomers and polymers

\section{Introduction}

In a dance, one to several participants may be involved. They can evolve in multicolored costumes in all kinds of formations, for example, two or more, in a chain or a circle. It seems interesting to adopt the idea of dance in the context of the arrangement of molecular blocks in the building of molecular systems; obviously, the blocks can be identical or different. Just as various dances can create varied feelings, the nature and arrangement of molecular blocks in the generated molecular system can induce quite different properties. Herein is described the obtaining of such "dancing" systems in which the colored azulene moieties (see Scheme 1) are involved without insisting on their properties and use, except for a few interesting pieces of information. Nonbenzenoid aromatic azulene has one less axis of symmetry compared with its benzenoid isomer naphthalene (Scheme 1). Although this difference decreases the stability of the azulene system, valuable properties are acquired that can be successfully used in technical applications. In a dancing system, the azulene moieties can be connected directly or a more or less complex spacer can be inserted between them.

The spacers described in the literature may provide a conjugation between the linked azulene, such as a double carbon bond or para positions of the benzene ring; $\mathrm{Csp}^{3}, \mathrm{Csp}^{2}$ atom, NH group, etc. can also be encountered as spacers. Several azulene moieties can form a linear oligomer or a polymer (compounds with structure A or B in Scheme 1). The involvement of azulene moieties in nonlinear molecules, such as crown ethers (compounds C), azulenophanes (compounds D1 and D2), calixazulenes (compounds E), or azuliporphyrins (compounds F) and similar derivatives (compounds G), is relatively new and intensely studied. The binding position of azulenes can be identical or different, leading to an impressive number of possible molecules. The use of the same positions or positions 2 and 6 (see Scheme 1) creates symmetry for the resulting large $\pi$-electron system with remarkable consequences on their properties. In turn, the asymmetric binding ensures the asymmetry 
of the electronic system. From the multitude of possible "dancing" azulene compounds that have been produced and studied so far, herein the interest is directed only at some less common compound classes, avoiding the classics presented extensively in the literature [1] The review was designed mainly with the intention of highlighting the wide variety of compounds that have azulene in their structure and to show how they were obtained.

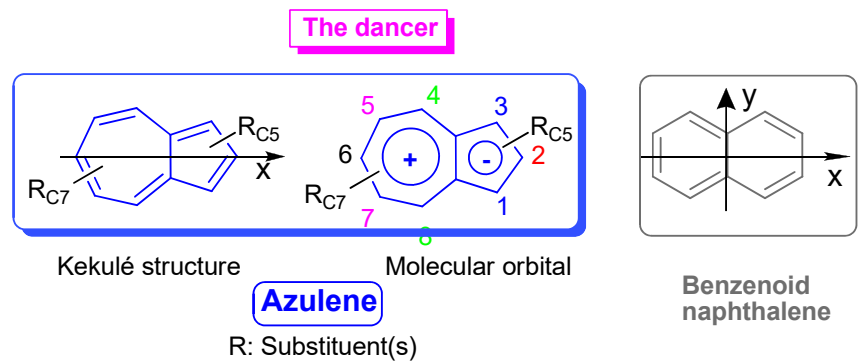

R: Substituent(s)

Dancing groups

Chain groups

azulene azulene

A1

$$
\text { azulene azulene }]_{\mathrm{n}}
$$

A2

azulene spacer-azulene

B1

B2

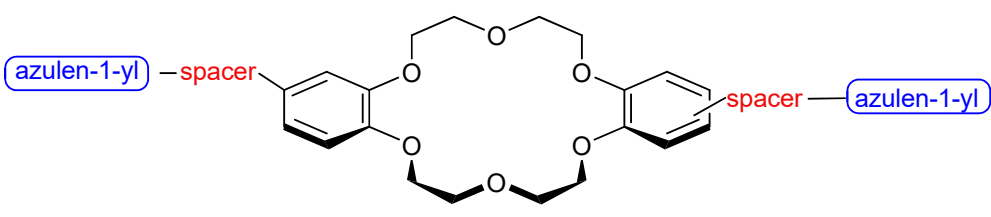

Circle groups

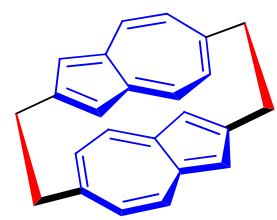

D1

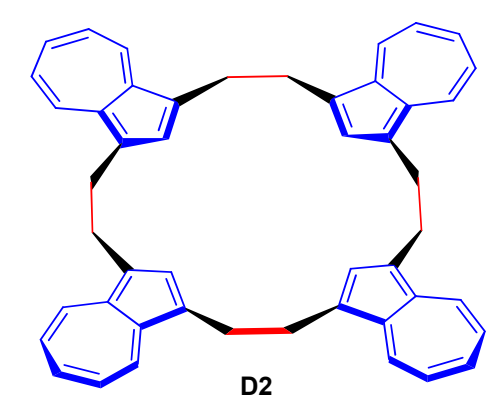

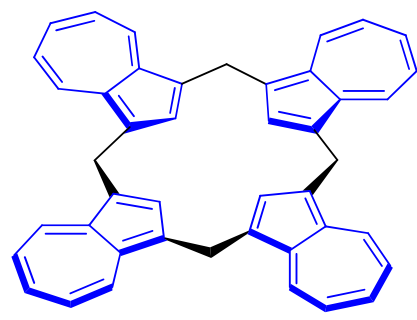

E

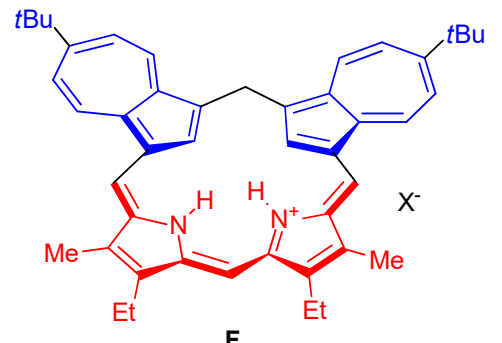

$\mathbf{F}$

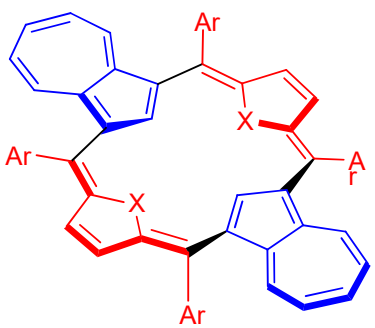

G: $\mathrm{X}, \mathrm{O}, \mathrm{S}$

Scheme 1. "Dancing" systems containing azulene moieties.

\section{The Dance of Two or More Azulenes without Any Spacers ("Dancing Groups" A)}

The enormous number of compounds containing two-connected azulenes that were obtained and studied over time is due to the number and nature of azulene substituents and to the positions used to link the participants. Usually, the synthesis of symmetrical biazulenyl derivatives that are coupled in identical positions occurs easily. However, 
when the coupling positions have very different electron charges, the synthesis pathway is more difficult. The annulation process and the coupling of two azulenes are the main routes for the preparation of biazulenyl-containing "dancing systems" of type A1 and even A2 (Scheme 1).

Several biazulenyl compounds, for example, the 5,5' - or 6,6'-coupled azulenes, which result from the cyclopentadiene annulation, follow the Ziegler-Hafner reaction [2]. Recently, the research teams of Razus [3] and Ito [4] obtained the unknown 1,6-coupled azulenes using the annulation. As described in Scheme 2, starting from pyranylium salts, the first team obtained the product in one step, whereas two steps were required starting from pyridinium salts by the second team. As it can be seen from Scheme 2, the last route allowed for obtaining product 8 of type $\mathbf{A} 2$.<smiles></smiles>

1

Rn: H or alkyl(s) $\mathrm{R}$ : $\mathrm{Me}$ or $\mathrm{Ph}$ $\mathrm{X}: \mathrm{CO}_{2} \mathrm{Et}, \mathrm{NHCOMe}$ Cp: cyclopentadienyl<smiles>[R]c1ccc2ccc(-c3ccncc3)c-2cc1</smiles>

4

$\mathrm{R}: \mathrm{H}$ or $t \mathrm{Bu}$<smiles></smiles>

2<smiles></smiles>

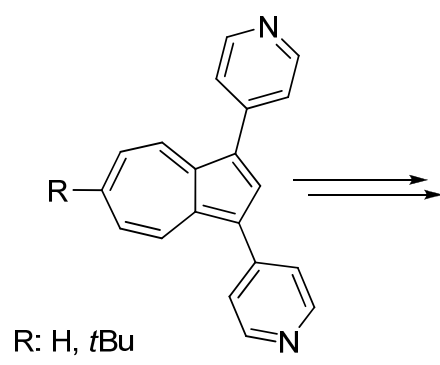

7

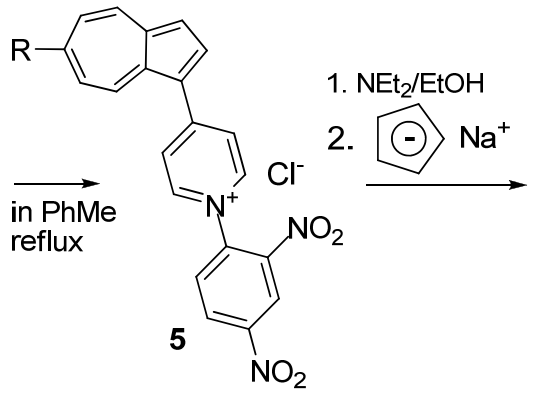<smiles>[R]c1ccc2ccc(-c3ccc4ccccc4c3)c-2cc1</smiles>

6

Scheme 2. Cyclopentadiene annulation following the Ziegler-Hafner route.

The more commonly used coupling process between azulenes can be realized through different routes and it is not the purpose of this review to exhaust all the material published in this field. Only several coupling reactions chosen based on the historical criterion or due to the interest presented by the synthesized products are presented.

(a) Old Ullmann condensation or dimerization to $1,1^{\prime}-, 2,2^{\prime}-, 1,2^{\prime}-$, or $2,6^{\prime}$-biazulenes and their derivatives were realized using the corresponding halogenated azulenes in the presence of activated copper in a sealed tube. Starting from a mixture of 1-bromo and 1,3-dibromoazulenes in the presence $\mathrm{NiCl}_{2} /\left(\mathrm{Ph}_{3} \mathrm{P}\right)_{2}, \mathrm{Zn}$, and $\mathrm{Et}_{4} \mathrm{NI}$ (in THF) [5], a mixture of 1,1'-biazulene and azulene oligomers was obtained [6]. 
(b) Electrochemical anodic oxidation [7,8] or chemical oxidation [9-11] of 1-substitued azulene. Due to the possibility to stabilize the positive charge as a tropylium moiety (intermediate radical cation 9), the azulene structure is favorable for one-electron elimination, as shown in Scheme 3. Thus, the electrochemical electron transfer gave compound 13, and compound 15 was generated when $\mathrm{FeCl}_{3}$ was used as the oxidant for compound 16. However, when the phenyl is not substituted at position 4 in compound 16, the coupling was directed in this position, which was more reactive than the azulene position 1, consequently, the "biazulene $\mathbf{1 7}^{\prime \prime}$ was produced with a biphenyl spacer.
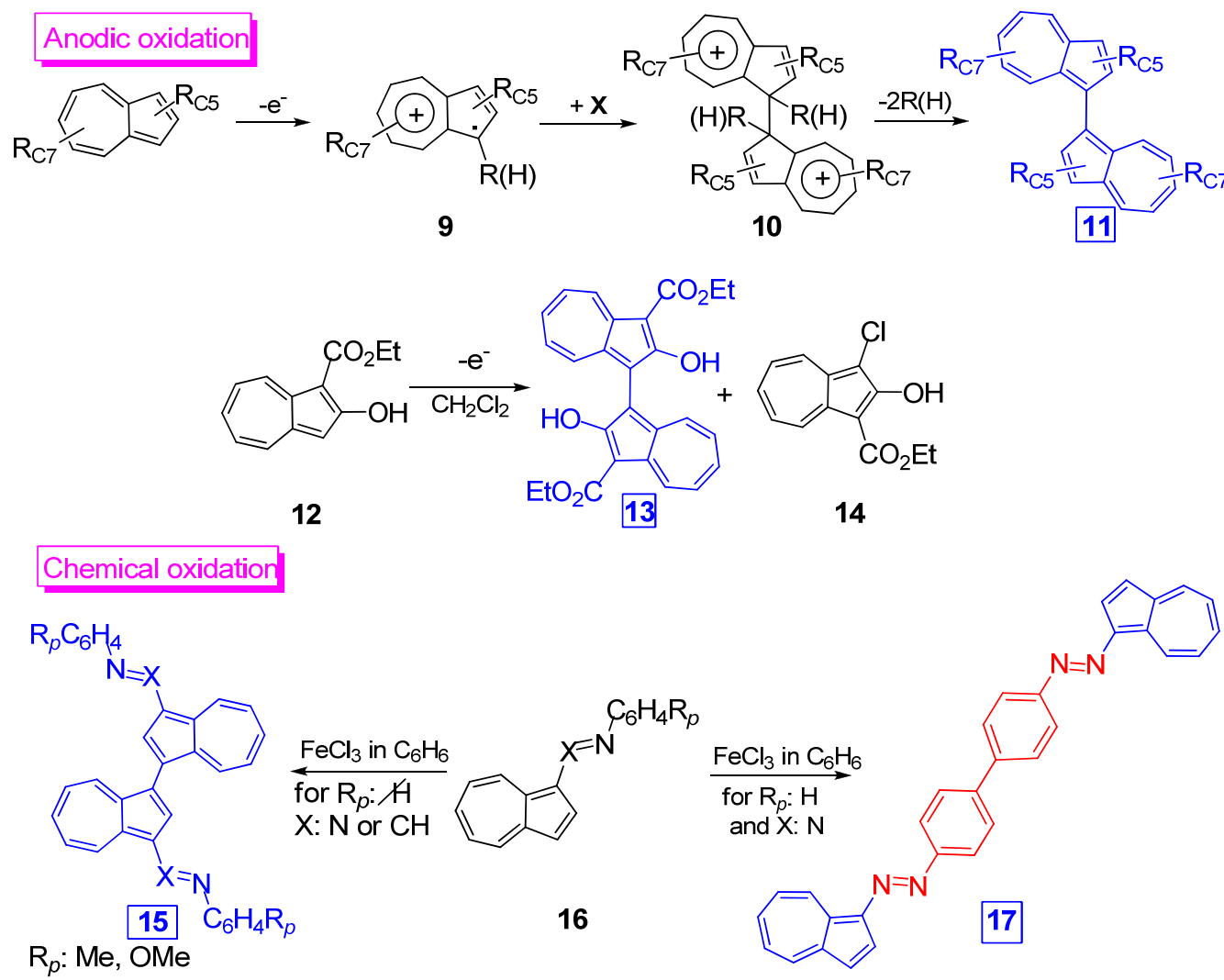

Scheme 3. Oxidative dimerization.

(c) Photoirradiation coupling of 1-azulenyl iodide with azulene in hexane [12]. The reaction proceeds regioselectively at the electron-rich 1-position with the elimination of iodine (azulene conversion 28\%; yield 67\%).

(d) Palladium-catalyzed intermolecular arylation of unsubstituted azulene [13]. Surprisingly, in an attempt to generate the azulene-Pd complex starting from azulene and palladium acetate, the 1,2'-biazulene was produced in a $10 \%$ yield.

Several cross-coupling reactions were also reported and were applied to obtain biazulenyl compounds of type A1; most of these reactions are transition-metal-mediated.

(a) The cross-coupling reaction of the organotin derivatives with electrophiles is palladium-catalyzed, known as the Stille reaction for carbon-carbon bond formation, was applied by Ito et al. [14] for the preparation of compounds $\mathbf{2 1}$ and 22. The reaction started from the 6-substituted azulenes with $n \mathrm{Bu}_{3} \mathrm{Sn}$ and azulenes with $\mathrm{Br}$ in 6 or 2 positions (Scheme 4). After several reaction steps, 2,2'-bisazulene 23 was also obtained with a good yield. 
<smiles></smiles>

18

R: $\mathrm{H}$ or $\mathrm{CO}_{2} \mathrm{Me}$

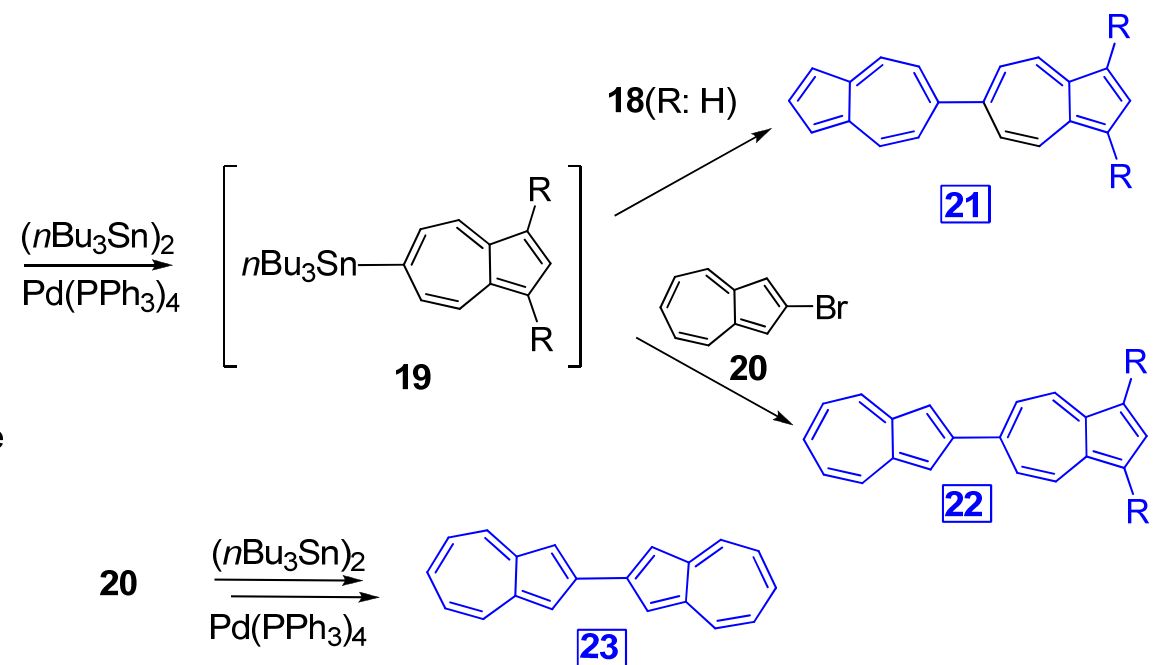

Piers coupling

2<smiles></smiles>

24

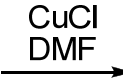

Pv: pivaloyl<smiles>CCCCOc1cccc2c(OCCC)cccc12</smiles>

25

Scheme 4. Stille and Piers coupling.

(b) The Piers variant [15] of the Stille reaction [16] in the presence of $\mathrm{CuCl}$ allowed for the synthesis of 4,4'-coupled azulene 25 .

(c) The Miyaura-Suzuki reaction of 1-azulenyl boronate with halogenoazulene derivatives $[16,17]$. Scheme 5 describes the route toward the azulenyl boronates $\mathbf{2 8}$ and $\mathbf{3 0}$ and their reaction with halogenoazulenes in the catalytic presence of palladium complexes. The bisazulenes $\mathbf{2 3}$ and $\mathbf{3 3}$ were produced in moderate yields from these reactions. Ito and colleagues reported the unexpected 2,2'-bisazulene formation as a major product, together with 2-(4-tolyl)azulene 29 in the reaction of boronate 28 with 4-chlorotoluene, whereas, using brominated toluene, the compound 29 was the only product. In similar reaction conditions, the azulene trimer $\mathbf{3 4}$, belonging to the compounds of type $\mathbf{A 2}$, was generated [16].

A series of biazulenes and terazulenes of type $\mathbf{A 1}$ and $\mathbf{A 2}$, presumed to have valuable technical properties (biazulenes 22 and 23 , and terazulenes $36-39$ from the Scheme 5) were produced after a sequence of Miyaura-Suzuki condensations [18,19]. The compounds 21 and 23 were also obtained by starting from the appropriate halogenated derivatives $\mathbf{1 8}$ and $\mathbf{4 0}$ in the nickel complex catalysis (Scheme 6) [20]. 


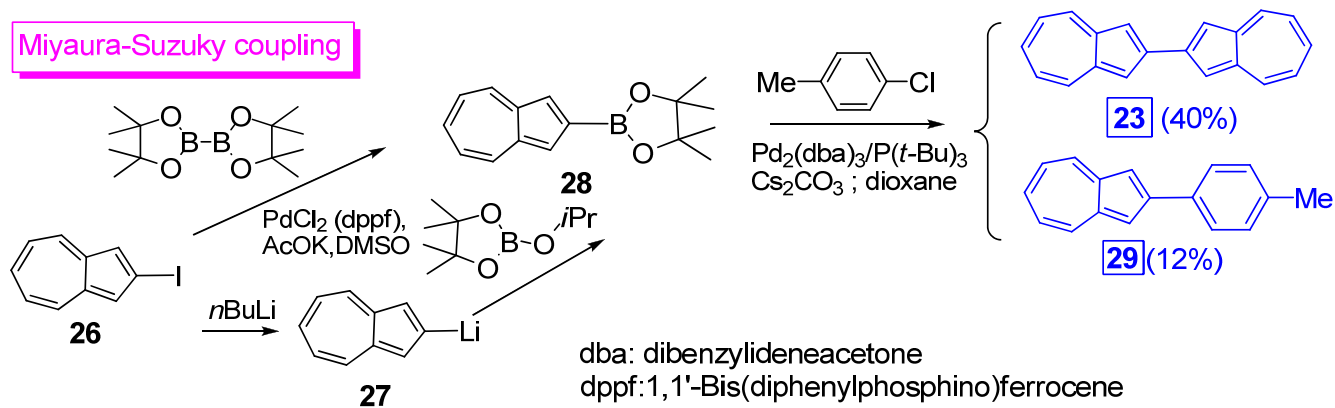

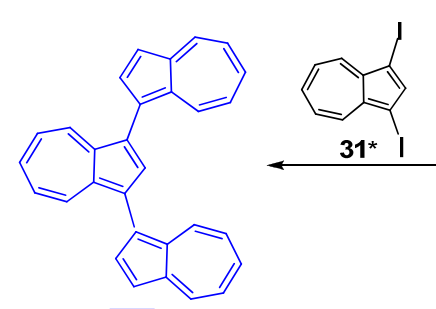

34

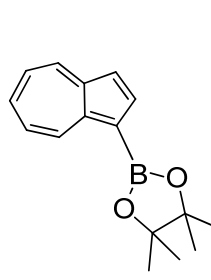

30

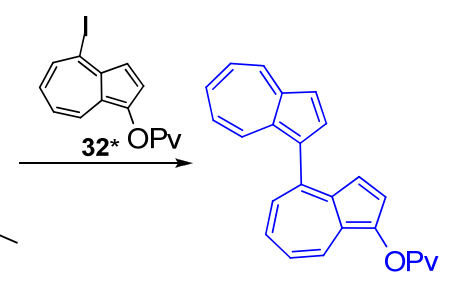

$33(27 \%)$

${ }^{*}$ Reaction conditions

$\mathrm{Pd}(\mathrm{OAc})_{2} / 2-($ Dicyclohexylphosphino)biphenyl

$\mathrm{Ba}(\mathrm{OH})_{2}$ in dioxane-water<smiles></smiles>

35

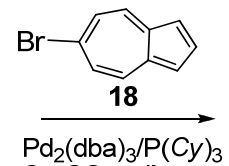

$\mathrm{Cs}_{2} \mathrm{CO}_{3}$; dioxane

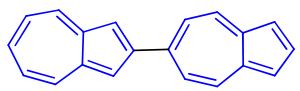

$22(30 \%)$

\section{Terazulenes obtained by Miyaura-Suzuky coupling}

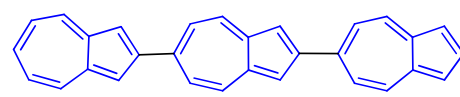

36

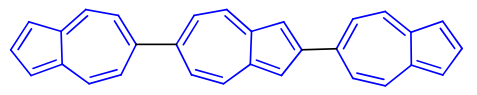

38

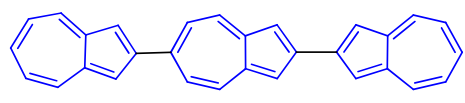

37

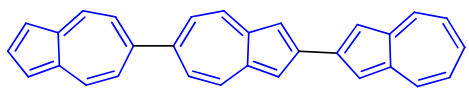

39

Scheme 5. Miyaura-Suzuki reaction of azulene-1-yl boronate.

2<smiles>Brc1ccc2cccc-2cc1</smiles>

18

2<smiles>Clc1cc2cccccc-2c1</smiles>

40

$\underset{\mathrm{DMF} / \mathrm{Zn}}{\stackrel{\mathrm{NiCl}_{2} / \mathrm{PPh}_{3}}{\longrightarrow}}$<smiles></smiles>

$21(29 \%)$

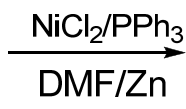

$\mathrm{DMF} / \mathrm{Zn}$

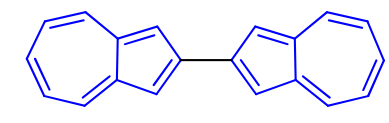

$23(20 \%)$

Scheme 6. Nickel-complex-promoted coupling.

The effects of the molecular and packing structure of some linear biazulenes on the optoelectronic and charge-transport properties were studied, demonstrating the importance of molecular structure and orbital symmetries [20]. Thus, 2,2'-biazulene 23 and 2,6-connected 
terazulene 36 possess properties of high-performance organic field-effect transistor (OFET) materials, and the alternating seven and five rings in the dimer 22 or trimer $\mathbf{3 6}$ favors potential NLO (nonlinear optical) features.

A somewhat more complicated bisazulenic system with valuable photophysical properties and are promising for organic electronic materials, namely, the $2,2^{\prime}$-biazulene- $1,1^{\prime}, 3,3^{\prime}$ tetracarboxylic diimides $43^{\prime}$ and $46^{\prime}$, contain a 2,2'-bisazulene moiety [21,22]. The 2,2'bisazulene 42 was produced via the dimerization of 2-chloroazulene 41 and the subsequent steps generated anhydride 43 and, finally, the diimide $43^{\prime}$. The same valuable properties were reported for compound $4 \mathbf{6}^{\prime}$ with four coupled azulenes synthesized, as described in Scheme 7.<smiles></smiles>

41

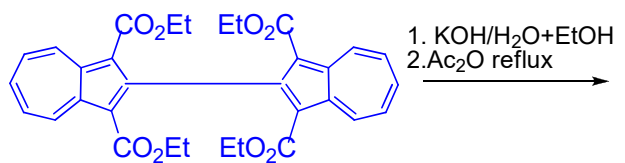

42

$\mathrm{Ni}(\mathrm{COD})_{2}$ : bis(1,5-cyclooctadiene)nickel(0)

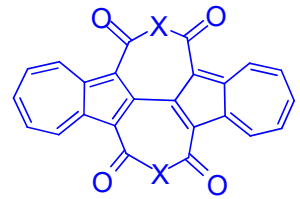

$43 \mathrm{X}: \mathrm{O}$<smiles></smiles>

44

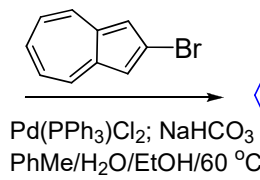
$\mathrm{PhMe} / \mathrm{H}_{2} \mathrm{O} / \mathrm{EtOH} / 60^{\circ} \mathrm{C}$<smiles></smiles>

. 2. $\mathrm{Ac}_{2} \mathrm{O}$ reflux

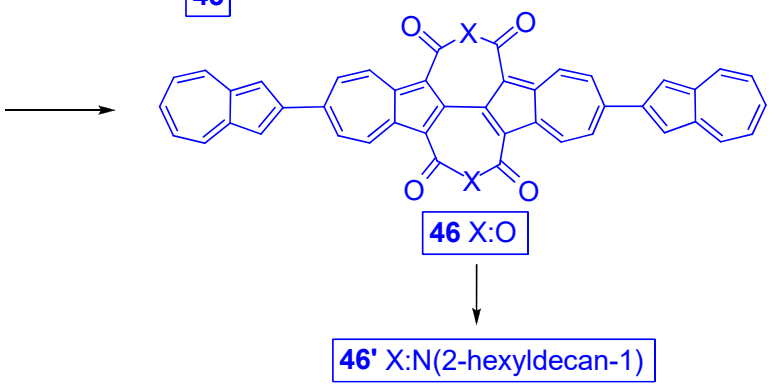

Scheme 7. Synthesis of dianhydride 43 and 46, which were used as precursors of the corresponding diimides $43^{\prime}$ and $46^{\prime}$.

The coupling of two azulenes (47) in position 1, avoiding the transition metal catalysis $[23,24]$, is worth examining. The used reaction steps are shown in Scheme 8 and the importance of the described procedure consists of the multitude of compounds that can be derived from compound 48. Interestingly, the proposed dimerization mechanism involves the azulene radical cation as the intermediate (see Scheme 3).

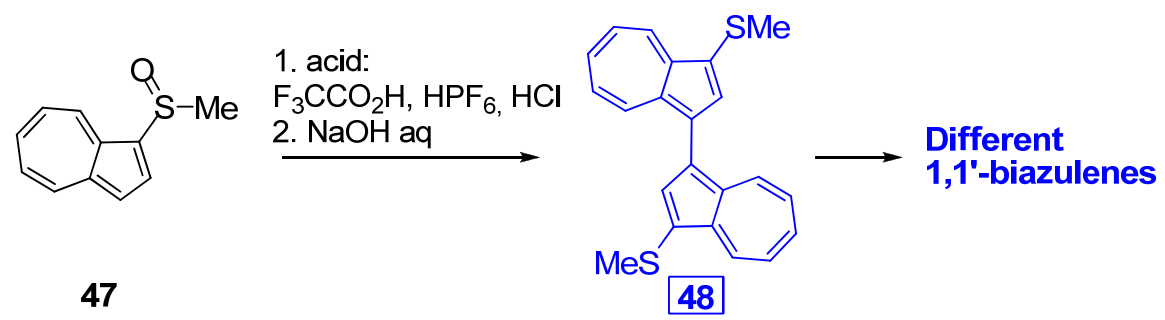

Scheme 8. Coupling of two azulenes in position 1, avoiding the transition metal catalysis.

At the end of this chapter, another member of the "dancing chain group" is mentioned, namely, polyazulene, due to its interest as a material with optical and electrical properties for the design of molecular devices. From the countless number of studies undertaken in this field, only a few representative ones will be selected. The chemical synthesis of 
electroactive and partially soluble polyazulene was realized via the chemical oxidative polymerization of azulene with iodine and bromine [25], with $\mathrm{FeCl}_{3}$ [26], or via the polymerization of 1,3-dibromoazulene with $\mathrm{Ni}(\mathrm{COD})_{2}$ [27]. Electrochemical polymerization was also used with significant results $[28,29]$. The electronic and structural properties of azulene-based polymers [30] and their optoelectronic and energy applications [31] were carefully investigated. After polymerization, the azulene units remain unchanged when coupling occurs in the 1,3 positions, as described in Scheme 9 for polyazulene 49 . Remarkably, the protonation of 1,3-polyazulene by trifluoroacetic acid has high conductivity and paramagnetic property+es as a result after the generation of radical cations $\mathbf{5 0}$ and $\mathbf{5 1}$ (polarons); by increasing the acidity, polycations $\mathbf{5 2}$ were formed $[27,30]$.

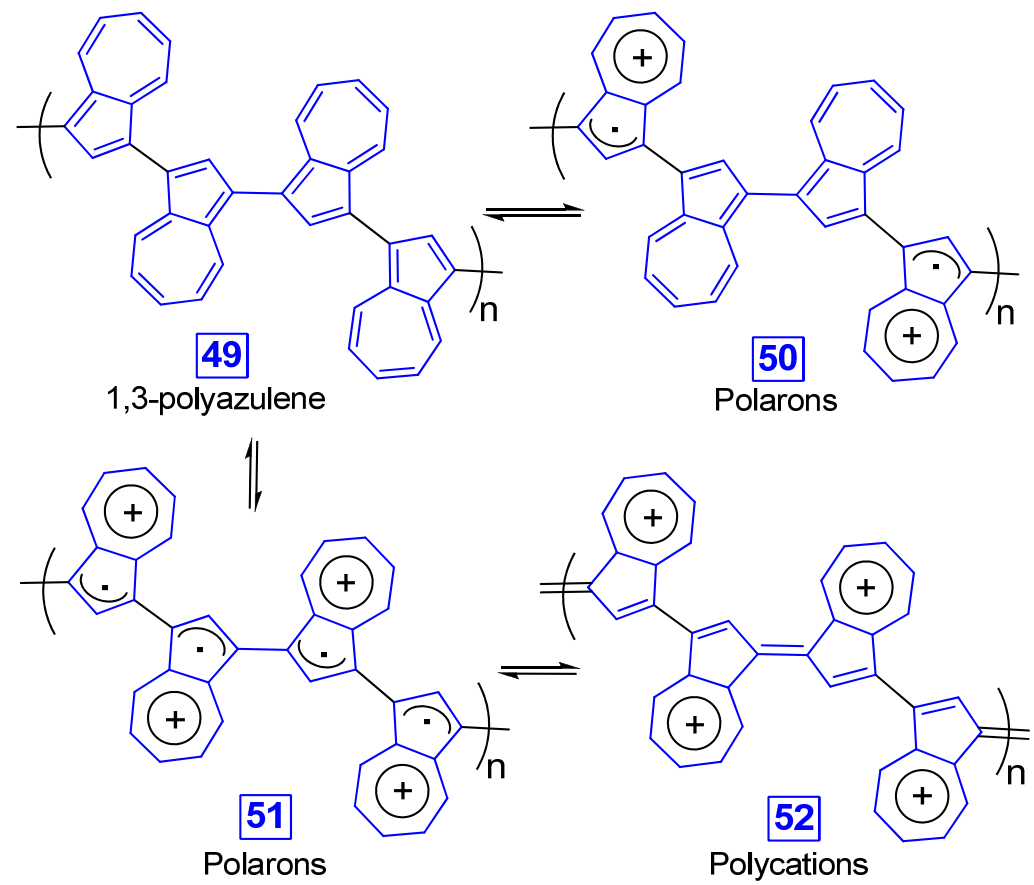

Scheme 9. The behavior of polyazelune in the acidic medium.

Very recently, the polymerization of azulene in positions 2,6 was successfully carried out and the interesting properties of the afforded polymer for the application as functional materials were studied. The new "on-surface synthesis" developed as a complementary strategy for chemical synthesis was used for generating homopolymers starting from 2,6-diiodoazulene [32] or 2,6-dibromoazulene [33] on $\mathrm{Au}[111]$.

\section{The Dance of Two or More Azulenes with Various Spacers ("Dancing Groups" B and C)}

Although examples of compounds in which a wide variety of azulenes are directly related to each other are far from exhausted, we move on to compounds with spacers interspersed between azulenes (Scheme 1). In these compounds, in addition to the multitude of azulene building blocks, there is a large variety of spacers that can be present. This specific feature and the scientific and applied interest presented by these compounds have led to an intense interest in the field. The characteristics and importance of this type of molecule were examined in several articles and a review published in 2020, which lists some recent information about such systems [34]. Therefore, in this section, only a few relevant aspects related to the compounds of "dancing" groups $\mathbf{B}$ and C, especially those related to the compound synthesis, will be highlighted.

First, substituted $\mathrm{Csp}^{3}$ and $\mathrm{Csp}^{2}$ can be mentioned as very simple spacers (Scheme 10). The coupling of 1-iodide in DMF at $85-90{ }^{\circ} \mathrm{C}$ afforded a mixture of 1-azulenmethylene oligomers 53, with saturated carbon as a spacer [35]. The involvement of a $\mathrm{Csp}^{2}$ atom near the azulenyl moieties in compounds of type $\mathbf{B}$ and $\mathbf{C}$ was largely discussed in a published 
review by Razus in the Symmetry journal [36]. Thus, the electron donor property of azulene as a stabilizer for the positive charge as in compounds $\mathbf{5 4}$ was emphasized. However, the presence of a $\mathrm{Csp}^{2}$ atom belonging to ethene between two azulenes as in compound 55 after cation $54(\mathrm{Q}=$ methyl) stabilization is interesting [37].

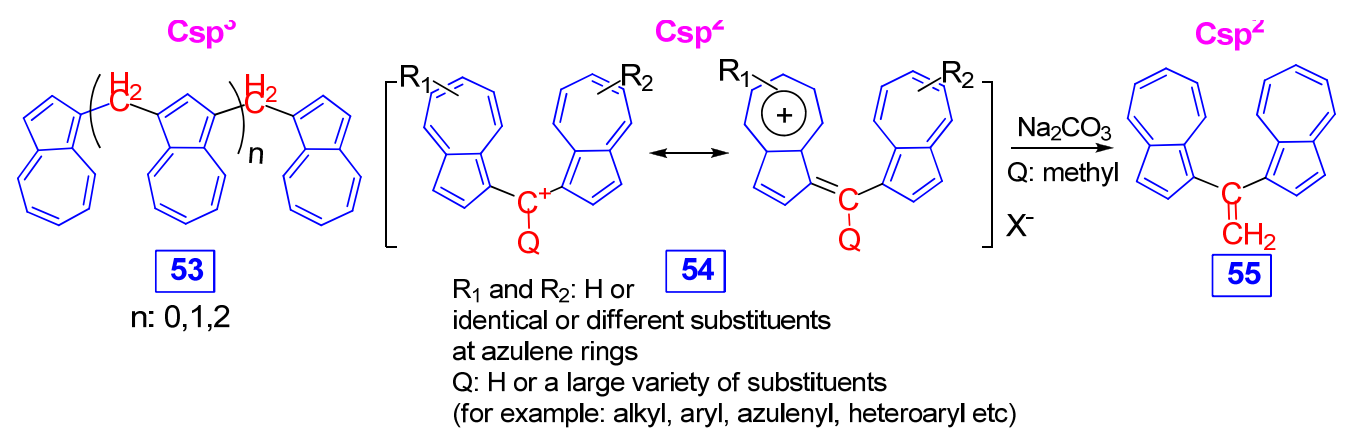

Scheme 10. Csp ${ }^{3}$ and $\mathrm{Csp}^{2}$ as a spacer between azulene moieties.

An extensive discussion in azulene chemistry is focused on the study of $\mathrm{C}=\mathrm{C}$ bond(s) substituted with azulene. The interest is related to the possibility of these compounds working as a metal due to their insignificant oxidation potentials. In Scheme 11, the important classical procedures for the synthesis of 1,2-biazulenyl ethenes and $\alpha, \omega$-biazulenyl polyenes [38] are depicted. For the less common isomers with the azulene coupled in 2,6 or 6,6 positions, namely, 61 or $\mathbf{6 2}$, Hunig and Ort used the Horner-Emmons reaction of phosphonate 63 with aldehydes with success [1]. The coupling in the 2,2 positions (compound 56) was realized using the Wittig route, starting from phosphonium salt 58 and corresponding aldehydes in severe reaction conditions and with moderate-to-good yields [1]. A more favorable reaction was shown to be the McMurry condensation between two aldehydes (57 or 60 ) catalyzed using $\mathrm{Ti}(0)$ from the perspective of the reaction conditions, as well as from the yields obtained. However, insufficient data on the mechanism of the last condensation procedure suggests the need for enlargement of the research on this topic [39]. At the beginning, 1-acetylazulene reacted in the presence of $\mathrm{TiCl}_{4}-\mathrm{Zn}$ and the results are described in Scheme 12.

The pyridine was added in several experiments and a series of attempts were performed that involved heating the reaction mixture under microwave irradiation. Surprisingly, a mixture of alkene 65 and pinacol 66 and the product of pinacol/pinacolone transposition 67 were produced in a ratio that depended on the reaction conditions, as described in Scheme 12. The proposed mechanism, based on the reaction results, which postulates the structures IA and IB as intermediates, is also summarized in Scheme 12.

The interesting results obtained encouraged the extension of the reaction to intramolecular condensation $[40,41]$. Thus, a series of carbocycles and heterocycles comprising 1,2-diazulenylethene moieties 69, 72, and 74 (Scheme 13), which are difficult to obtain from other reaction routes, was synthesized. The reported results highlight the decisive influence of azulene substituents on the product mixture, in addition to the reaction conditions. As a general tendency, the preponderance of alkene and pinacolic transposition compounds in the product mixture to the detriment of the pinacole can be observed. As expected, the closing of the four-atom ring with a double bond (compound 74) was found to be particularly unfavorable such that cyclobutene was obtained only with a yield below $10 \%$. Unfortunately, a broader discussion on these topics cannot be developed in this review. An advantage of the described McMurry route consists in the possibility to generate heteroaromatic furan and thiophene $\mathbf{7 6}(\mathrm{X}=\mathrm{O}$ or $\mathrm{S})$ starting from the corresponding alkenes 77 $(\mathrm{X}=\mathrm{O}$ or $\mathrm{S})$ (Scheme 13) [40]. 


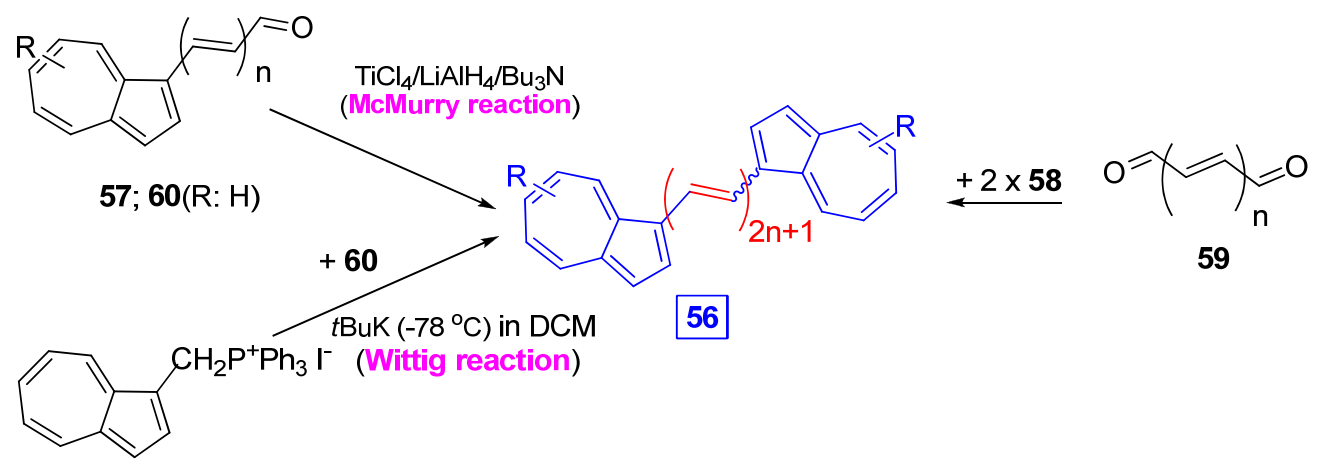

58
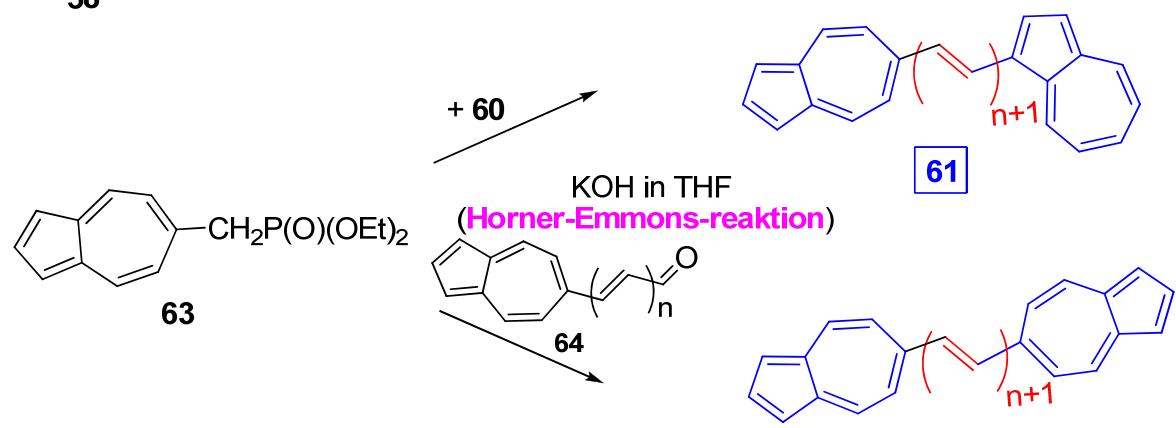

62

Scheme 11. $\alpha, \omega$-Biazulenyl polyenes syntheses $(C=C$ present as a spacer(s)).

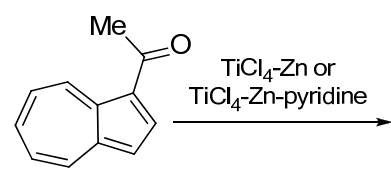

64<smiles>CC(C(C)=C1C=Cc2ccccc21)=C1C=Cc2ccccc21</smiles>

65<smiles>CC(O)(O)C(C)(O)c1cc2ccccc3cccc-3c-2c1</smiles>

$66 d /$<smiles></smiles>

Yield (\%) 65 (E:Z) $66 d l 67$ trace $89 \quad 3$ $35(12: 88) \quad 38 \quad 7$ $34(7: 93) \quad 12 \quad 44$ $40(7: 93) \quad-\quad 42$

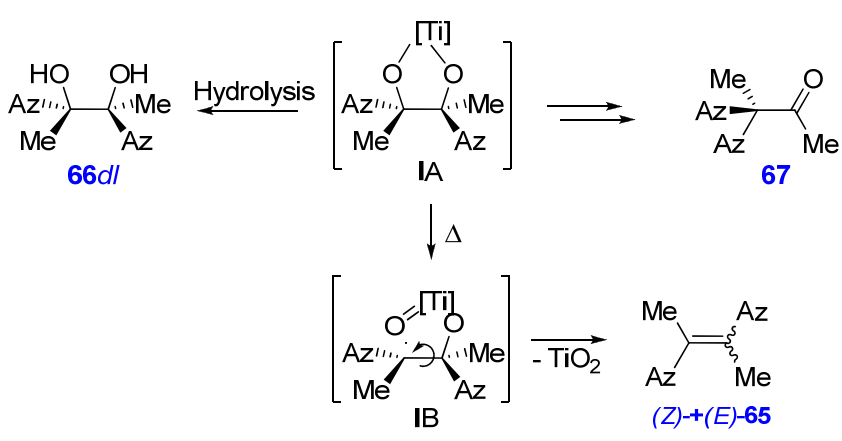

Scheme 12. McMurry reaction of 1-acetylazulene in the presence of $\mathrm{TiCl}_{4}-\mathrm{Zn}$ or $\mathrm{TiCl}_{4}-\mathrm{Zn}$-pyridine. 
<smiles>[Y10]C1=C([Y10])CCC1</smiles>

69<smiles>[Y20]C1([Z10])CCCC1=O</smiles>

70<smiles>[Y10]C1(O)CCCCC1(O)CCC1CCCC1</smiles>

n: 3<smiles>[Y20]C(=O)CCC(C)=O</smiles><smiles>[Al]C1=C([Te])CCCC1</smiles>

72

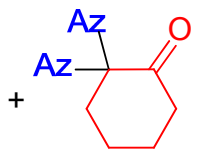

73

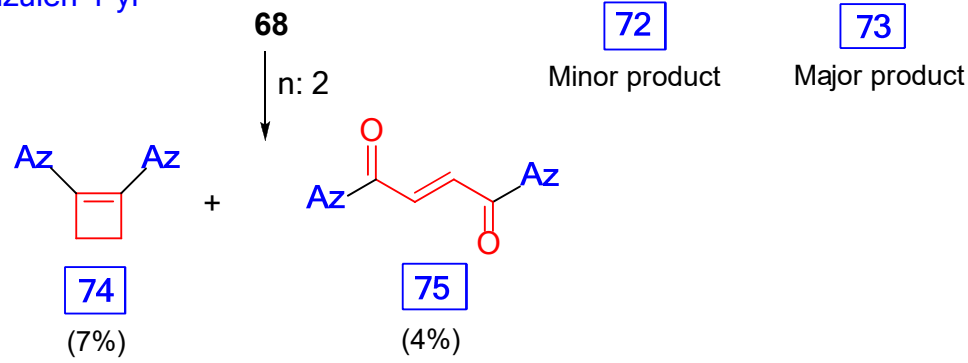<smiles>[R16]C([Y10])=O</smiles>

76

Az: azulen-1-yl $\mathrm{X}$ : O or $\mathrm{S}$<smiles></smiles>

$77 \mathrm{X}$ Major products<smiles>[Y]C1([Y10])C[CH+]C(=O)C1</smiles>

$78 \mathrm{X}$<smiles>[Y]CC1([Y20])C[14CH2]C1([Y20])O</smiles><smiles>[Y20]c1cc([Y20])cc([Te][3H])c1</smiles>

Scheme 13. McMurry intramolecular coupling.

In an attempt to synthesize cyclooctatetraene derivative fused by two azulenes, Shoji et al. tried closing the ring in the intermediate ethene $\mathbf{8 1}$ substituted with two azulenes (Scheme 14) [42]. This intermediate resulted in an aldol condensation between carbonyl in position 1 and methyl in position 2 of the azulene compound $\mathbf{8 2}$.

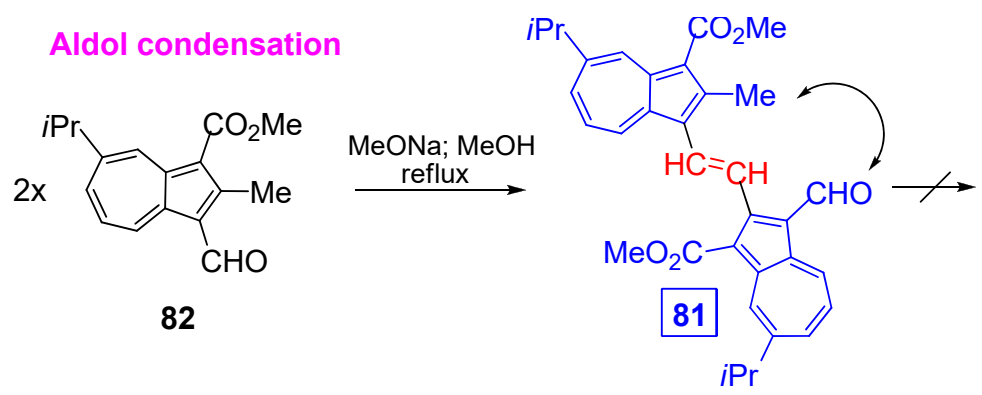

Scheme 14. Aldol condensation between carbonyl and methyl substituents at the azulene.

In a comprehensive article on substituted 1-azulenylethenes, the condensation of a Schiff base with 1-azuleneacetic acid produced 1,2-diazulenylethene (Schiff base conversion $40 \%$ and yield $81 \%$ ) (Scheme 15) [43]. 
<smiles>Cl/N=C/c1ccc2cccccc1-2</smiles>

83
${ }_{6} \mathrm{H}_{4}(\mathrm{OMe}) p$

$+\mathrm{AzCH}_{2} \mathrm{COOH}$

84

Az: azulen-1-y

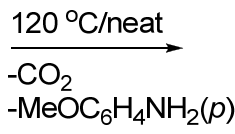

$-\mathrm{MeOC}_{6} \mathrm{H}_{4} \mathrm{NH}_{2}(p)$

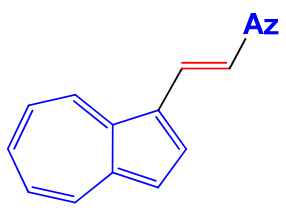

(E) 85

Scheme 15. Condensation of a Schiff base with 1-azuleneacetic acid.

The substitution of positions 1,2 or 1,4 in benzene ensures a continuous conjugation of the substituents grafted in these positions. Scheme 16 provides some examples of the benzene spacer substituted with 2- or 6-azulenyl groups. For the preparation of products, the already described procedures, namely, Stille and Miyaura-Suzuki coupling, were considered [14,17]. Interestingly, the condensations afforded, together with the attempted compound, the product of substitution with $n \mathrm{Bu}$ and even that which resulted after bromine elimination, i.e., compounds $\mathbf{8 8}, \mathbf{9 1}$, and $\mathbf{9 6}$, respectively. The yields of products were between moderate and low. The Miyaura-Suzuki reaction proceeded better, although the polysubstituted products resulted in a reduced amount.

Stille coupling reaction

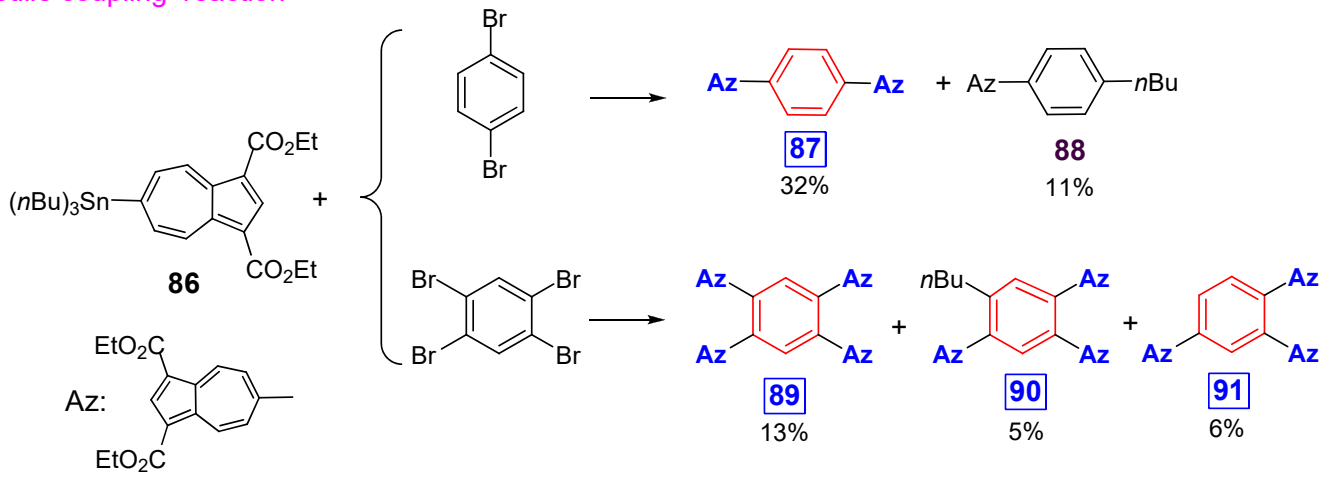

Miyaura-Suzuki coupling reaction

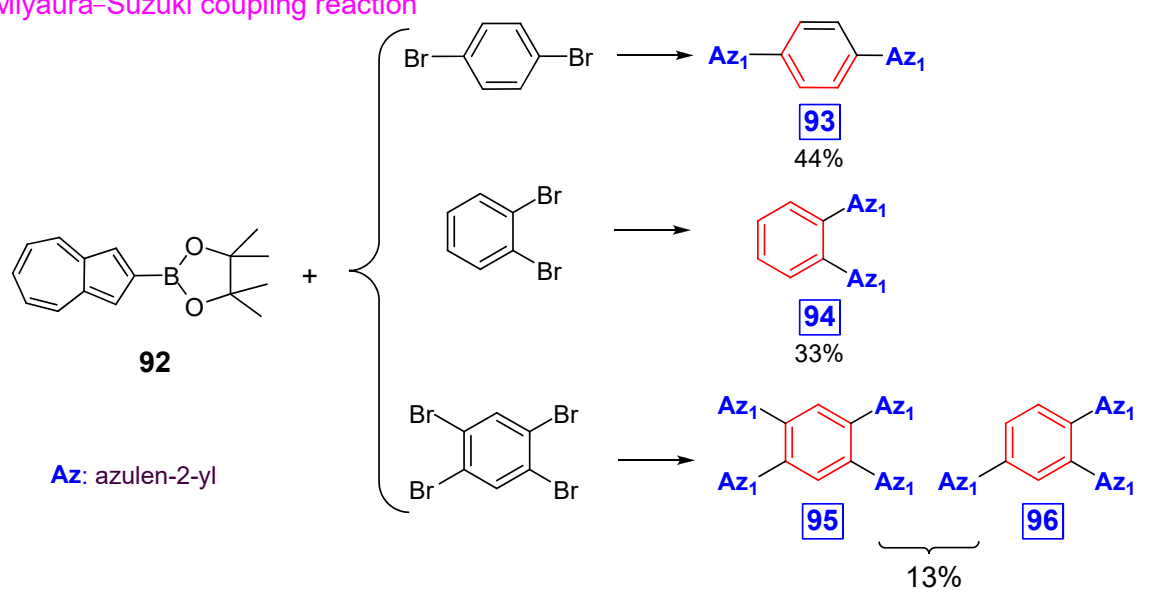

Scheme 16. Benzene as a spacer between azulene moieties.

Naphthalene as a spacer was also found in the literature, and in Scheme 17, the synthesis of such a product is exemplified [44]. The azulenophthalimides as the compounds $64^{\prime}$ and $\mathbf{9 8}$ displayed a significant spectral change under electrochemical reduction conditions, which are interesting for technical applications. 
<smiles>[R]N1Oc2c(Br)c(Br)c3c4c(c(Br)c(Br)c(c24)O1)ON([R])O3</smiles>

97

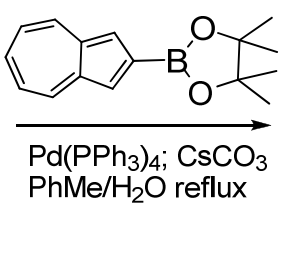

$\mathrm{R}:-\mathrm{C}_{8} \mathrm{H}_{17}$<smiles></smiles>

98

Scheme 17. Naphthalene as a spacer between azulene moieties.

Aromatic heterocycles can also play the role of a spacer between azulene. Several optoelectronic and energy applications of such compounds were presented in a review published in 2020 [31]. One example was already given in Scheme 13, namely, the furan and thiophene $\mathbf{8 0}(\mathrm{X}=\mathrm{O}$ and $\mathrm{S})$. Examples of pyridine or pyrilium compounds $\mathbf{1 0 0}$ and 101 were obtained using the Miyaura-Suzuki route, as described in Scheme 18, starting from the corresponding dibromide derivatives [45]. Scheme 18 also provides an example of the synthesis of terazulene $\mathbf{1 0 2}$ with the central azulene substituted in position 2 with 6-azulenylazulene.<smiles></smiles>

100

Reaction conditions $\left(\mathrm{Ph}_{3} \mathrm{P}\right)_{2} \mathrm{PdCl}_{2}, \mathrm{Ba}(\mathrm{OH})_{2}$ DME- $\mathrm{H}_{2} \mathrm{O}(50: 1)$, reflux<smiles>CCOC(=O)c1c2ccc(-c3ccc(-c4ccc5c(C(=O)OCC)c(N)c(C(=O)OCC)c-5cc4)n3C(=O)OCc3ccccc3)ccc-2c(C(=O)OCC)c1N</smiles><smiles>C=C(C)B1OC(C)(C)C(C)(CC)O1</smiles><smiles></smiles><smiles></smiles><smiles></smiles><smiles></smiles>

102

Scheme 18. Aromatic heterocycles substituted by azulenes.

From the large number of compounds containing a heteroaromatic spacer between azulenes, a few are highlighted only as prototypes because a comprehensive review about this series of compounds has recently appeared [34,46]. In Schemes 19-21, there are several examples of such compounds with their synthesis. The phosphole compound 104 was obtained using the Stille coupling method, starting from 2,5-bis(tri-nbutylstannyl)phosphole 103 (Scheme 19) [47]. 


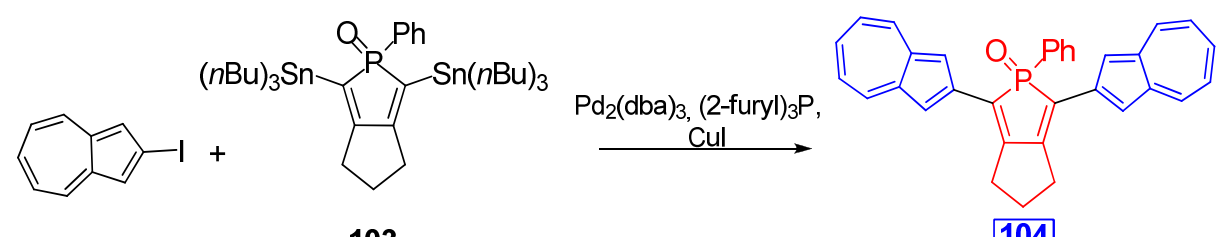

103

Scheme 19. Phosphole moiety as a spacer between azulenes.<smiles></smiles>

105

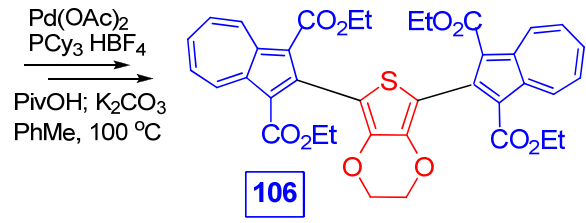

106<smiles></smiles>

107

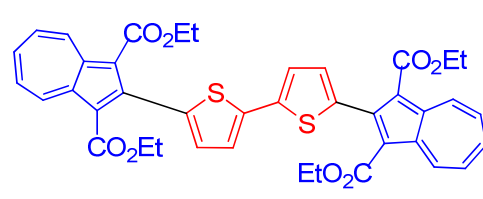

108

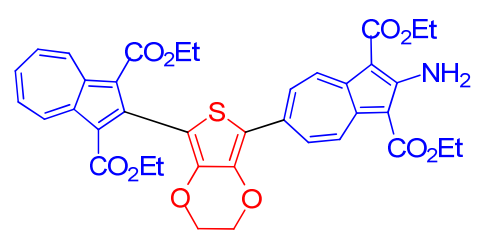

109<smiles></smiles>

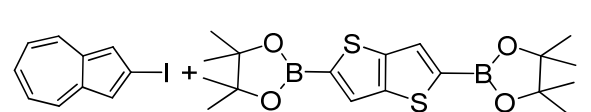

112
$\mathrm{Pd}\left(\mathrm{PPh}_{3}\right) \mathrm{Cl}_{2} ; \mathrm{NaHCO}_{3}$ $\stackrel{\mathrm{PhMe} / \mathrm{H}_{2} \mathrm{O} / \mathrm{EtOH}}{\longrightarrow}$

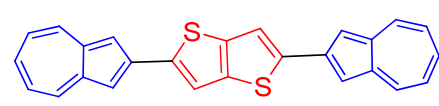

113

Scheme 20. Sulfur-containing heteroaromatic compounds as spacers between azulenes.

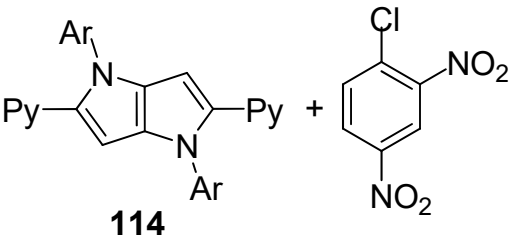
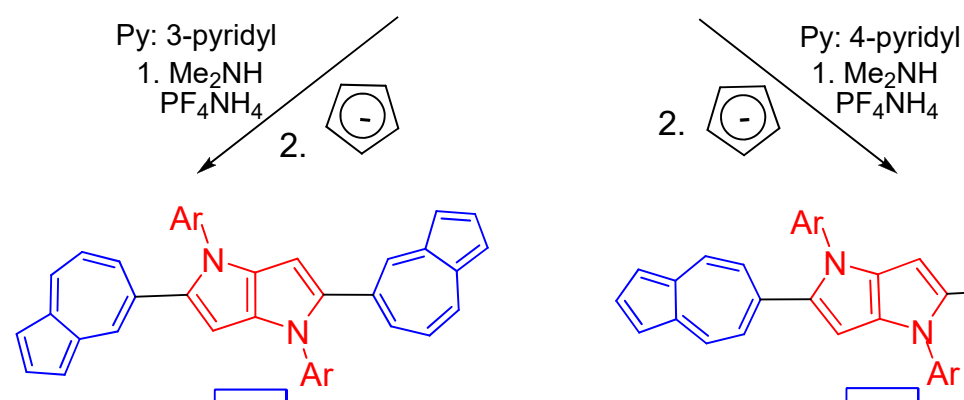

115

$\mathrm{Ar}=4$-tolyl

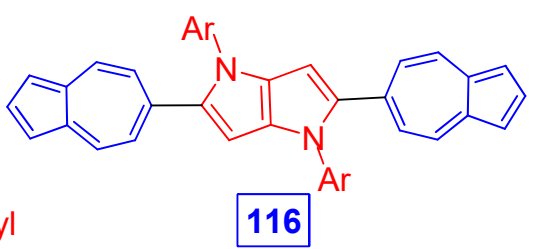

Scheme 21. Nitrogen-containing heteroaromatic compound as a spacer between azulenes. 
More commonly encountered are the compounds with sulfur-containing heterocycle(s) as spacers (Scheme 20) due to their potential use in electronic devices based on their features in organic field-effect transistors (OFETs) [48].

The reaction route for the generation of compound 106 starts from 3,4-ethylenedioxythiophene (EDOT) 105 and occurs in two successive steps with mono and second substitution of a thiophene ring (yield 81\%). Other compounds with thiophene spacer(s), namely, 107-109, were achieved in the same way with excellent yields. The same technical application was also assumed for compounds 111 and 113. For the first compound, Stille condensation of bis-stannane 110 with azulene was used [16], and Miyaura-Suzuki condensation of thienothiophene diboronic acid ester 112 with 2-iodoazulene afforded the product 113 (Scheme 20) [49].

The quatropolar acceptor-donor-acceptor dye structure of compounds $\mathbf{1 1 5}$ and $\mathbf{1 1 6}$ with a pyrrolo[3,2-b]pyrroles spacer between azulenes stimulated the synthesis of these products (Scheme 21). The chosen pathway was different from those discussed for the analog sulfur-containing compound $\mathbf{1 1 3}$ and followed the building of azulene moieties accordingly the Ziegler-Hafner route [50] described above [2].

The ability of azulene to stabilize positive charge suggested to Razus et al. the use of this moiety to increase the stability of the heteroaromatic cations as such for pyrylium and pyridinium salts. The obtained results were reported in a detailed review [51]; therefore, only a few data on these studies are presented in Scheme 22. The syntheses are based on the condensation of aldehydes with a reactive methyl group in the presence of a dehydrating agent as acetic anhydride [51]. The reaction of 1-azulencarbaldeydes with 2,6-dimethyl substituted 4-(azulen-1-yl)pyrylium salt 117 affords a mixture of products. A mixture of products also provided the reaction of 2,4,6-trimethylpyrylium salt 120 . Both series of products contain the pyryliumvinyl(s) moieties as spacers. The total yields were good, but only traces of completely condensed products $\mathbf{1 1 9}$ or $\mathbf{1 2 3}$ were formed after heating the reaction mixture. However, microwave-assisted reactions selectively generated the fully condensed compound.

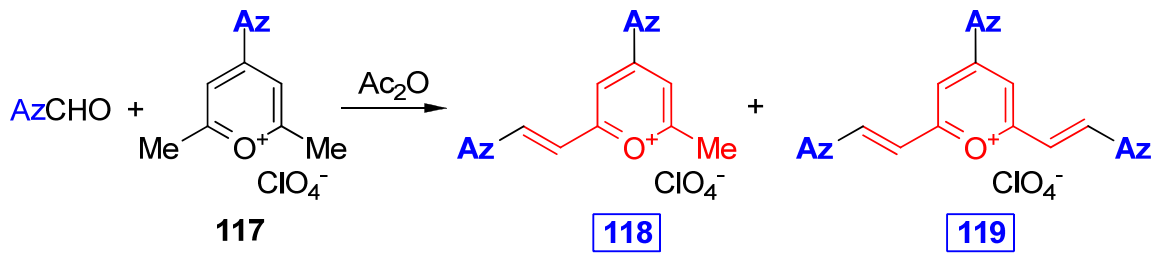

Az: azulen-1-yl, 4,6,8-trimethylazulen-1-yl

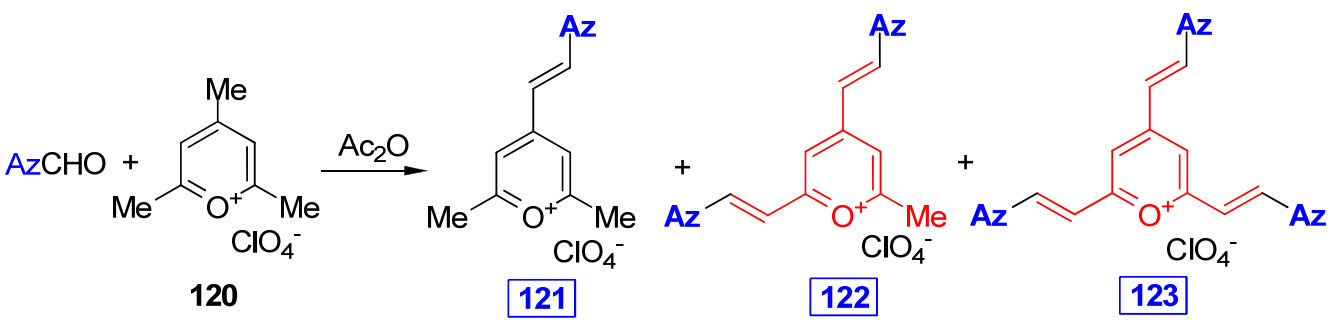

Az: azulen-1-yl, 4,6,8-trimethylazulen-1-yl or guaiazulen-1-yl

Scheme 22. Pyrylium vinyl cation as a spacer between azulenes.

An interesting class of spacers includes the crown ethers, which are known for their use in chemical and biomedical purposes. Because they are colorless, the introduction of the azulene chromophore in the structure ensures a color that allows their easier detection. An example of the introduction of azulene into the crown ether ring was described by Löhr et al. [52]. The dibenzocrown ether $\mathbf{1 2 5}$ was used as a support for the azulene moieties and the connection between them was realized with spacer $\mathrm{C}=\mathrm{C}$ or $\mathrm{N}=\mathrm{N}$ bonds, as described in Scheme 23 . The 
bisvinylazulene 124 was achieved via the Wittig route, starting from the dibenzocrown 125, by passing through the dialdehyde intermediary 126 [53]. The bisazoderivatives 127 was produced via diazotization of the intermediate diamine 128 [54]. Unfortunately, the reaction starting from compound $\mathbf{1 2 5}$ does not work regiospecifically and the condensation with aldehyde occurred with the generation of both geometric isomers. However, for several practical applications, this does not seem to be a problem. The reported yields for both reactions were good to moderate.

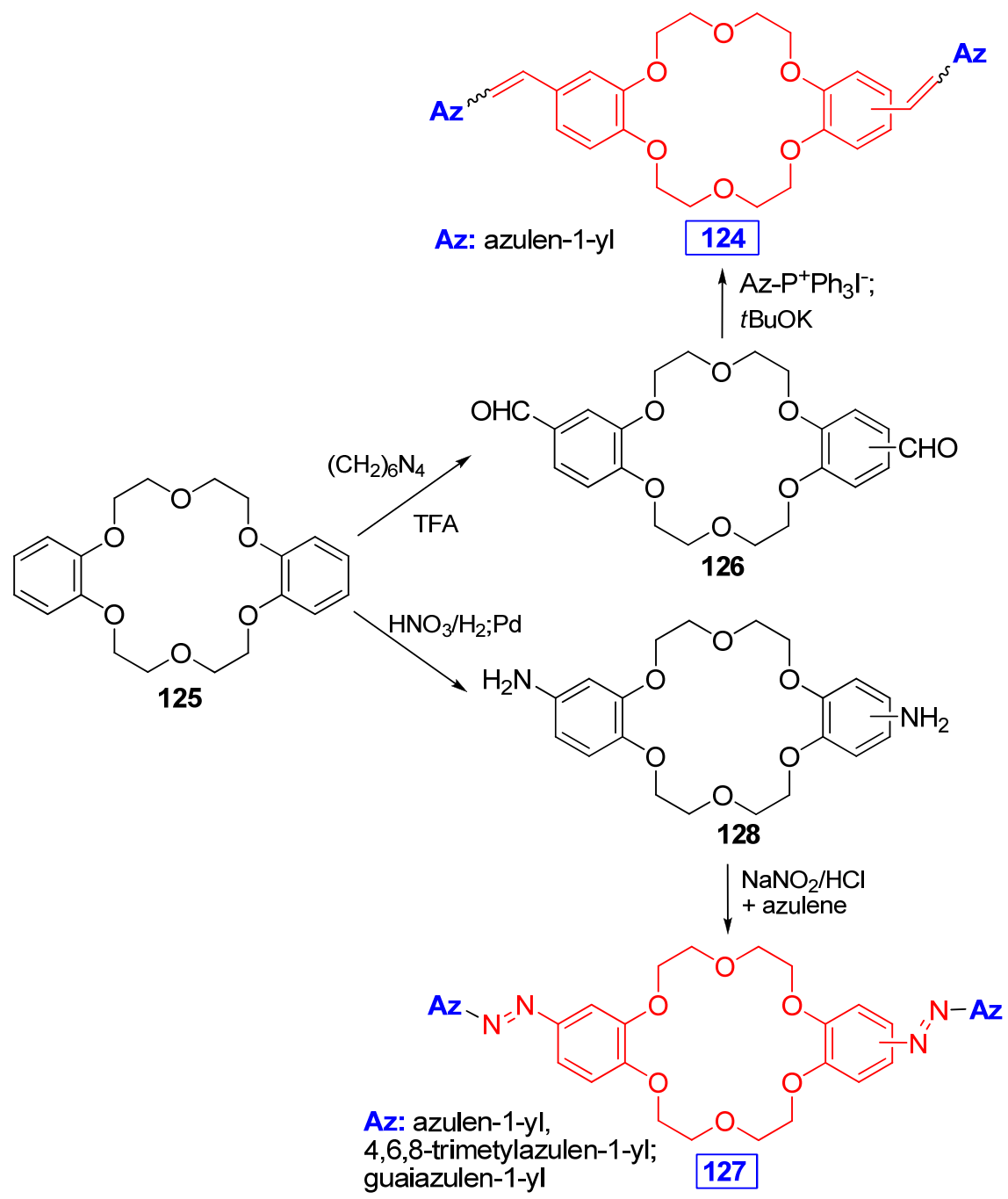

Scheme 23. Benzocrown ethers with 1-azulenylvinyl or azulenylazo substituents.

In large reviews of azulene compounds with importance in the field of optoelectronics $[31,55]$, the authors focused their concerns also on azulene-based copolymers with different spacers. The non-alternant structure of azulene induces a small HOMO-LUMO bandgap with beneficial consequences on the practical applications of compounds containing azulene(s), for example, for NLO devices. According to their structure, these compounds can also be considered as belonging to category "chain dancing group" B2, as shown in Scheme 24, which contains some examples of such structures. The polymers were obtained via chemical [56-58] or electrochemical routes [59] (polymers 129-130 or polymer 131, respectively). Several among the attempted chemical syntheses for achieving dimers or oligomers were aforementioned. Azulene-containing polymers have also attracted interest in the fields of materials chemistry and pharmaceutical sciences. However, a more detailed treatment of these subjects exceeds the intended purpose of this review. 
<smiles></smiles>

R: $\mathrm{C}_{10} \mathrm{H}_{21}$ or $\mathrm{OC}_{12} \mathrm{H}_{25}$

$129 a$<smiles>Cc1cc2cc(N)cc-2ccc1Nc1cc2ccc(Br)ccc-2c1</smiles>

130

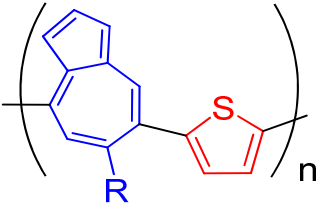

R: $\mathrm{C}_{12} \mathrm{H}_{25}$<smiles>Cc1ccc(/C=C/c2cc(C)c3cccccc2-3)s1</smiles>

Scheme 24. Azulene-based copolymers.

\section{The Dancing Circle Groups ("Dancing Groups" D and E)}

This section surveys a few interesting pieces of information, although older, on anti[2.2](2,6)-azulenophane 134 (Scheme 25) [60,61] and [2.2.2.2](1,3)-azulenophane 138 [35]. It seems strange that the azulenophane 134 in which two dipolar rings are facing each other did not receive more attention. The Hofmann pyrolysis of salt $\mathbf{1 3 2}$ afforded the target compound 134 through the intermediate 133; however, the yield was $9-11 \%$.

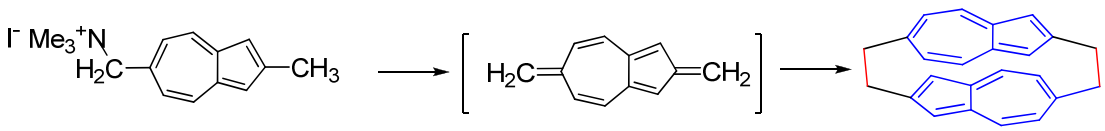

132

133

134

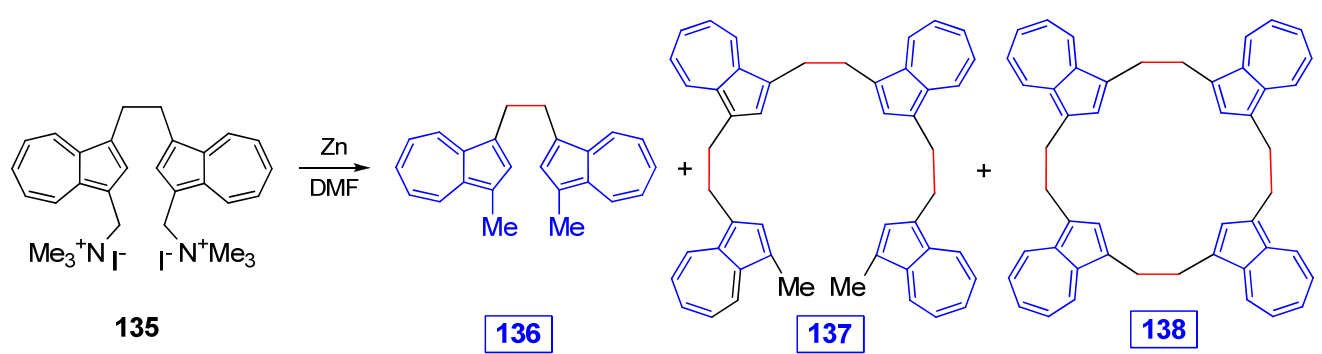

Scheme 25. Azulenophanes.

As it can be seen, compound 138 belongs to the "dancing circle group" (Scheme 1) while compounds 136 and 137 belong to the "the chain group." The double salt 135 in DMF in the presence of $\mathrm{Zn}$ powder formed a high amount of polymer; however, after careful processing of the reaction mixture, the compounds 136-138 were separated in amounts that only allowed for the products' characterization (yields $\sim 1 \%$ ).

In contrast, the tridimensional calixazulenes (Scheme 26) received much more attention and a recent comprehensive paper, where Georghiou et al. deals extensively with this topic [62]. The supramolecular relationships between bowl-shaped calixarenes and the fullerenes with the potential for encapsulating $C_{60}$ or $C_{70}$ fullerenes have stimulated the interest of chemists [63]. 


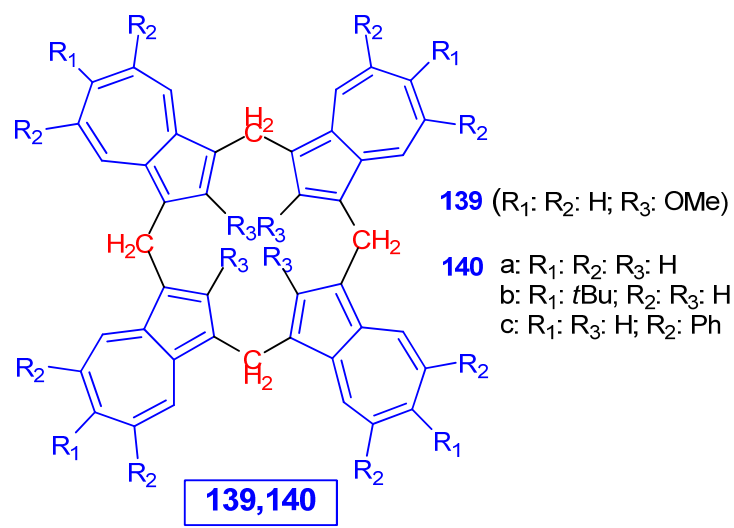

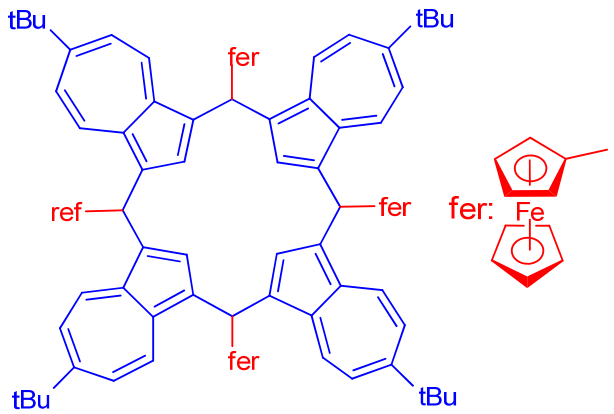

141

Scheme 26. Calixazulenes.

Asao et al. reported the generation of compound $\mathbf{1 3 9}$ with a 20\% yield after successive condensations of 2-methoxyazulene and formaldehyde [64]. Subsequently, Lash succeeded in the synthesis of the all-hydrocarbon calix[4]azulenes 140a and 140b by performing the condensation of azulene or $6-t \mathrm{Bu}$ azulene with paraformaldehyde in the presence of Florisil ${ }^{\circledR}[65,66]$ with good results. In [62], Georghiou obtained the bulky calixarene 140c. The spacer methylene in calixarene can be also substituted. Thus, the peculiar ferrocenylmethylene-bridged calix[4]azulene 141 was obtained with moderate yield as the main product with an amount of bis(1-azulenyl)ferrocenylmethane derivative using the reaction of 6-tert-butylazulene with ferrocenecarbaldehyde in acetic acid [67]. Products similar to compound $\mathbf{1 4 1}$ with phenyl, $p$-tolyl, and $p$-methoxyphenyl instead of ferrocene [68] were also obtained.

\section{The Dancing Circle Group of Azuliporphyrins and Similar Compounds ("Dancing Group" F)}

One of the most studied "dancing groups" (Scheme 1) is that with the core porphyrin modified by the replacement of one to all pyrroles with azulene or where the azulene moieties were substituted at the methylene groups of porphyrin. As a result, the number and complexity of products that can be obtained are very high. The reviews and articles that have appeared in this field are impressive. Therefore, here, the data of only a few aspects, especially those related to the synthesis of these products, are covered for information purposes.

Regarding the aim to investigate the extensively conjugated porphyrin with promising two-photon absorption (TPA), compound 143 (both atropisomers) was synthesized starting from dipyrrolmethane 142 (Scheme 26). The two oxidative rings closing (under the Scholl conditions) in intermediate 143 toward the target product $\mathrm{Ni}^{2+}-5,15$-bis(4azulenyl)porphyrin $\mathbf{1 4 4}$ was due to the electron-rich position 3 in azulene [69]. Interestingly, complex $\mathbf{1 4 4}$ has a symmetric anti structure. When the Ar in Scheme 27 was also 1-methoxycarbonylazulene, the same sequence was used to form a very large conjugated quadruply azulene-fused porphyrin. Kurotobi realized a compound with porphyrin that was core-substituted with four 6-azulenyl moieties at the methylene groups using the Ziegler-Natta procedure for the building azulene moieties from the corresponding pyridine [70]. 


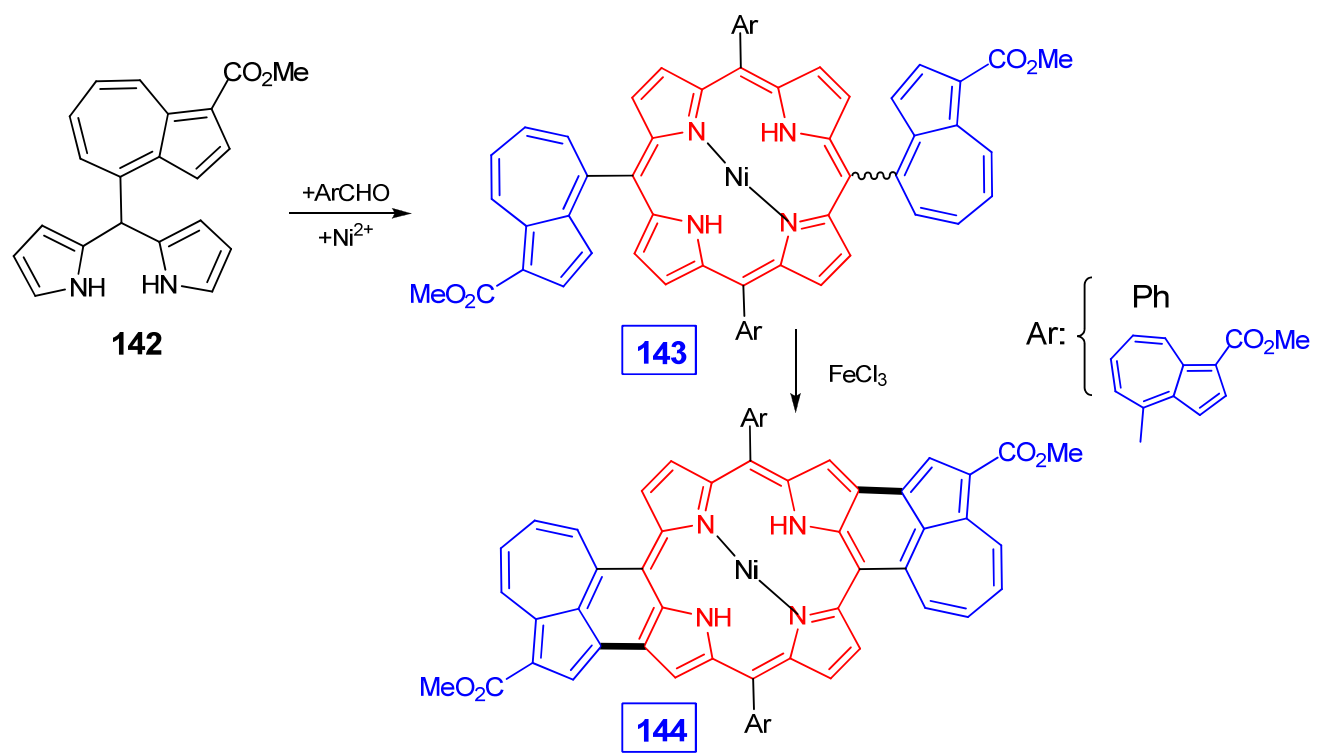

Scheme 27. Synthesis and closing of $\mathrm{Ni}^{2+}-5,15$-bis(4-azulenyl)porphyrin.

The intermediate aromatic properties of azuliporphyrins result in special reactivity and physical properties, for example, strange spectroscopic behavior. The possibility to achieve highly extended $\pi$-electron conjugation over pyrroles and azulenes incorporated into the porphyrin skeleton has been of interest to researchers. A careful investigation into the structure of azuliporphyrine with one or two azulenes in the porphyrin ring, based mainly on spectral results, was carried out by Lash et al. [71,72]. Thus, two azulenes were inserted into the porphyrin ring in the adj position, namely, side by side. The adj isomer 147 was achieved, as described in Scheme 28, by coupling the dialdehyde 145 with dipyrrylmethane $\mathbf{1 4 6}$ and the subsequent oxidation of the formed intermediate with $\mathrm{FeCl}_{3}$ in the presence of $\mathrm{HCl}$ or $\mathrm{HBr}$. The zwitterionic canonic structure 147B leads to the $18 \pi-$ porphyrinoid macrocyclic aromaticity and tropylium configuration of a seven-membered ring of azulene with remarkable physico-chemical consequences.
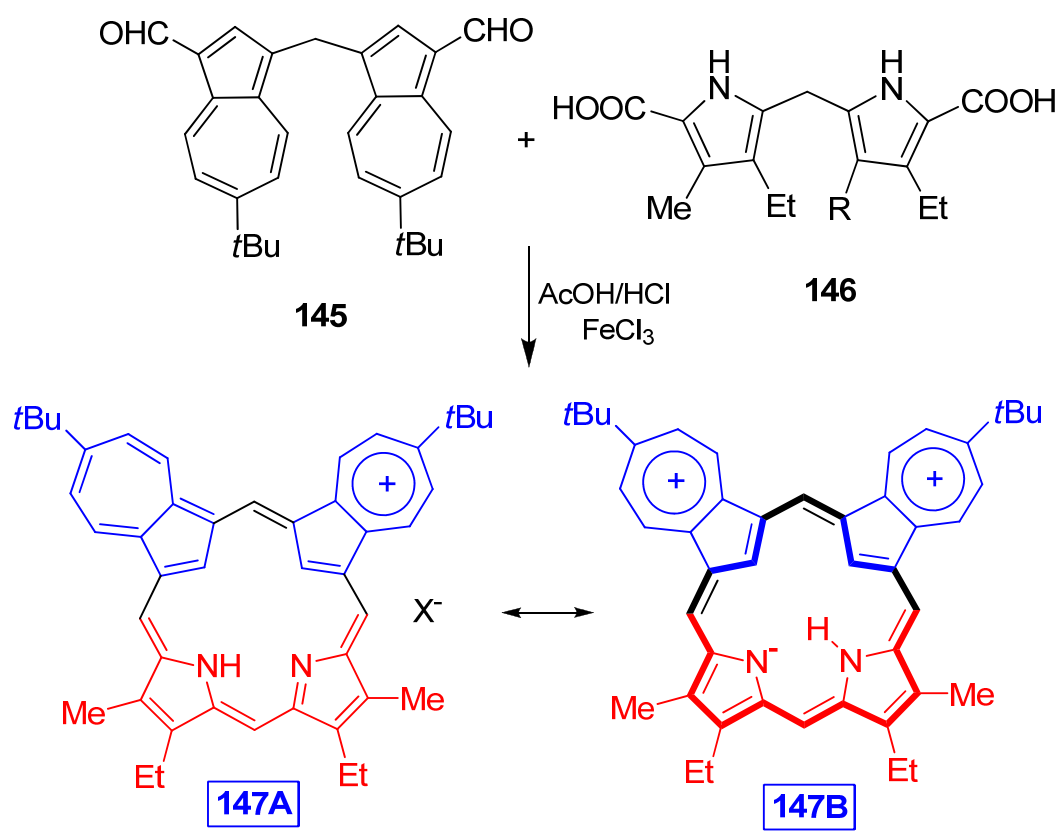

Scheme 28. Synthesis of azuliporphyrin. 
Finally, other peculiar molecules with extended $\pi$-electron conjugation, namely, hybrid thiophene- or furan-azulene macrocycles, are briefly discussed. Latos-Grazynski and coworkers synthesized dithiadiazuliporphyrin (150S) with a remarkable $91 \%$ yield using the Rothemund-type condensation described in Scheme 29 [73], and when the thiophene ring was replaced by furan, the compound $\mathbf{1 5 0 0}$ was produced [74]. Unlike the azulipyridines discussed above, the arrangement of the two azulenes in the min ring is anti. The oxidation of condensation intermediate 148 generates the dication 149 with an exceptional structure possessing an extended $\pi$-electron conjugation, together with two tropylium cations. The spectral consequences and other properties influenced by the structure of compounds 149 and 150, as well as the potential for applications in optoelectronics, electrochromic, and molecular conductivity, were discussed in detail in the mentioned articles.
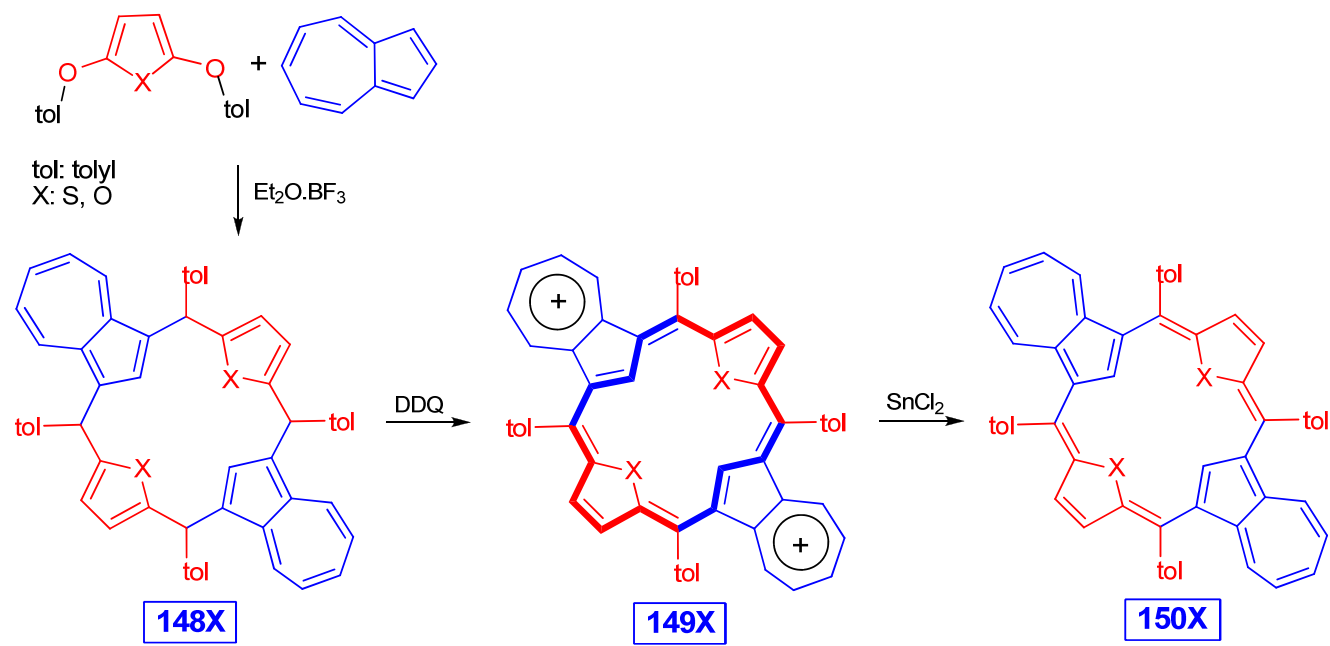

Scheme 29. Synthesis of dioxadiazuliporphyrin and dithiadiazuliporphyrin.

\section{Instead of Conclusions}

The article was designed out of love for the chemistry of azulene and its derivatives. It does not propose a systematic treatment of a particular topic but tries to cover several areas of this vast chemistry. To avoid "academic rigidity," a less common way of presenting the results belonging to the author and other researchers was preferred, namely, the introduction of azulenes as dancers in a series of dancing groups. In such groups, the connecting position of azulenes can be identical or different, and between azulenes, a spacer can be introduced, leading to an impressive number of possible molecules. Several azulene moieties can form a linear oligomer or a polymer, and the involvement of azulene moieties in nonlinear molecules, such as crown ethers (compounds $\mathbf{C}$ ), azulenophane (compounds D1 and D2), calixazulenes (compounds E), or azuliporphyrins (compounds F) and similar derivatives (compounds G), was intensely studied. Therefore, only some aspects were covered in this review, which were mainly related to the obtaining of azulene compounds and less to their characterization or physico-chemical properties. The review is addressed less to those skilled in azulene chemistry but instead mainly to researchers who want to know something about this fascinating field or maybe even to approach it.

Funding: This research received no external funding.

Institutional Review Board Statement: Not applicable.

Informed Consent Statement: Not applicable.

Data Availability Statement: Data available in a publicly accessible repository.

Acknowledgments: The author is grateful to the late Klaus Hafner from the Institute of Organic Chemistry, Technische Universität Darmstadt, for helpful discussions. These discussions were very useful and will be remembered for a long time. 
Conflicts of Interest: The author declares no conflict of interest, financial or otherwise.

\section{References}

1. Zeller, K.-P. Houben Weyl, Methoden der Organischen Chemie; G. Thieme Verlag: Stuttgart, Germany; New York, NY, USA, 1985; Volume V/2c, pp. 258-263.

2. Hanke, M.; Jutz, C. Synthese von 6,6'-biazulenyl. Synthesis 1980, 31-32. [CrossRef]

3. Razus, A.C.; Pavel, C.; Lehadus, O.; Nica, S.; Corbu, A. Synthesis and properties of $\left[1,6^{\prime}\right]$ biazulenyl system. Tetrahedron 2008, 64, 1792-1797. [CrossRef]

4. Shoji, T.; Yamamoto, A.; Shimomura, E.; Maruyama, M.; Ito, S.; Okujima, T.; Toyota, K.; Morita, N. Synthesis of 1,6'-Bi- and

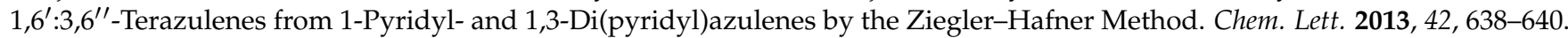
[CrossRef]

5. Iyoda, M.; Sato, K.; Oda, M. Nickel-catalyzed coupling of bromides of 1,6-methano[10]annulene and azulene. A facile synthesis of biannulene and bi-, ter-, quater-, and polyazulenes. Tetrahedron Lett. 1985, 26, 3829-3832. [CrossRef]

6. Morita, T.; Takase, K. Synthesis of 1,1'-, 2,2'-, 1,2'-, and 2,6'-Biazulenes and Their Derivatives by Ullmann Reaction. Bull. Chem. Soc. Jpn. 1982, 55, 1144-1152. [CrossRef]

7. Chen, A.H. Electrochemical Oxidation of 1,2-Disubstituted Azulenes. Proc. Natl. Sci. Counc. ROC(A) 1999, $23,437-442$.

8. Totir, N.D.; Razus, A.C.; Nitu, C.; Lete, C.; Lupu, S. Electrochemical and Chemical Oxidation of Derivatives of Azulene. In Proceedings of the 189th Meeting of the Electrochemical Society, Phoenix, AZ, USA, 22-27 October 2000.

9. Razus, A.C. Syntheses of polycyclic compounds by oxidative coupling of azulene-1-azoarenes. J. Chem. Soc. Perkin Trans. 1 2000, 6, 981-988. [CrossRef]

10. Razus, A.C.; Nitu, C. Oxidative benzylic substitution of azulene-1-azo(4'-methylbenzene)s. J. Chem. Soc. Perkin Trans. 1 2000, 6, 989-994. [CrossRef]

11. Razus, A.C.; Birzan, L.; Nae, S.; Tecuceanu, V.; Cimpeanu, V. 1,1'-Biazulene derivatives. Syntheses and reactions. Arkivoc 2002, II, 142-153. [CrossRef]

12. Ho, T.-I.; Ku, C.-K.; Liu, R.S.H. Preparation of 1-arylazulenes through regioselective photoarylation of azulene with aryl iodides. Tetrahedron Lett. 2001, 42, 715-717. [CrossRef]

13. Dyker, G.; Borowski, S.; Heiermann, J.; Körning, J.; Opwis, K.; Henkel, G.; Köckerling, M. First intermolecular palladium catalyzed arylation of an unfunctionalized aromatic hydrocarbon. J. Organomet. Chem. 2000, 606, 108-111. [CrossRef]

14. Ito, S.; Okujima, T.; Morita, N. Preparation and Stille cross-coupling reaction of the first organotin reagents of azulenes. Easy access to poly(azulen-6-yl)benzene derivatives. J. Chem. Soc. Perkin Trans. 1 2002, 1896-1905. [CrossRef]

15. Piers, E.; Yee, J.G.K.; Gladstone, P.L. CuCl-Mediated Intramolecular Oxidative Coupling of Aryl- and Alkenyltrimethylstannane Functions. Org. Lett. 2000, 2, 481-484. [CrossRef] [PubMed]

16. Crombie, A.L.; Kane, J.L.; Shea, A.K.M.; Danheiser, R.L. Ring Expansion-Annulation Strategy for the Synthesis of Substituted Azulenes and Oligoazulenes. 2. Synthesis of Azulenyl Halides, Sulfonates, and Azulenylmetal Compounds and Their Application in Transition-Metal-Mediated Coupling Reactions. J. Org. Chem. 2004, 69, 8652-8667. [CrossRef] [PubMed]

17. Ito, S.; Terazono, T.; Kubo, T.; Okujima, T.; Morita, N.; Murafuji, T.; Sugihara, Y.; Fujimori, K.; Kawakami, J.; Tajiri, A. Efficient preparation of 2-azulenylboronate and Miyaura-Suzuki cross-coupling reaction with aryl bromides for easy access to poly(2azulenyl)benzenes. Tetrahedron 2004, 60, 5357-5366. [CrossRef]

18. Yamaguchi, Y.; Ogawa, K.; Nakayama, K.-I.; Ohba, Y.; Katagiri, H. Terazulene: A High-Performance n-Type Organic Field-Effect Transistor Based on Molecular Orbital Distribution Control. J. Am. Chem. Soc. 2013, 135, 19095-19098. [CrossRef]

19. Yamaguchi, Y.; Takubo, M.; Ogawa, K.; Nakayama, K.-I.; Koganezawa, T.; Katagiri, H. Terazulene Isomers: Polarity Change of OFETs through Molecular Orbital Distribution Contrast. J. Am. Chem. Soc. 2016, 138, 11335-11343. [CrossRef]

20. Shibuya, Y.; Aonuma, K.; Kimura, T.; Kaneko, T.; Fujiwara, W.; Yamaguchi, Y.; Kumaki, D.; Tokito, S.; Katagiri, H. Linear Biazulene Isomers: Effects of Molecular and Packing Structure on Optoelectronic and Charge-Transport Properties. J. Phys. Chem. C 2020, 124, 4738-4746. [CrossRef]

21. Xin, H.; Ge, C.; Yang, X.; Gao, H.; Yang, X.; Gao, X. Biazulene diimides: A new building block for organic electronic materials. Chem. Sci. 2016, 7, 6701-6705. [CrossRef]

22. Xin, H.; Li, J.; Ge, C.; Yang, X.; Xue, T.; Gao, X. 6,6'-Diaryl-substituted biazulene diimides for solution-processable highperformance n-type organic semiconductors. Mater. Chem. Front. 2018, 2, 975-985. [CrossRef]

23. Shoji, T.; Ito, S.; Toyota, K.; Yasunami, M.; Morita, N. The novel transition metal free synthesis of 1,1'-biazulene. Tetrahedron Lett. 2007, 48, 4999-5002. [CrossRef]

24. Shoji, T.; Higashi, J.; Ito, S.; Toyota, K.; Asao, T.; Yasunami, M.; Fujimori, K.; Morita, N. Synthesis and Redox Behavior of 1-Azulenyl Sulfides and Efficient Synthesis of 1,1'-Biazulenes. Eur. J. Org. Chem. 2008, 1242-1252. [CrossRef]

25. Neoh, K.G.; Kang, E.-T.; Tan, T. Chemical synthesis and characterization of electroactive and partially soluble polyazulene. Polym. Bull. 1988, 19, 325-331. [CrossRef]

26. Grądzka, E.; Makowska, P.; Winkler, K. Chemically formed conducting polyazulene: From micro- to nanostructures. Synth. Met. 2018, 246, 115-121. [CrossRef]

27. Wang, F.; Lai, Y.-H.; Kocherginsky, A.N.M.; Kosteski, Y.Y. The First Fully Characterized 1,3-Polyazulene: High Electrical Conductivity Resulting from Cation Radicals and Polycations Generated upon Protonation. Org. Lett. 2003, 5, 995-998. [CrossRef] 
28. Bargon, J.; Mohmand, S.; Waltman, R.J. Polyazulene, A Member of a New Class of Polymers. Mol. Cryst. Liq. Cryst. 1983, 93, 279-291. [CrossRef]

29. Oprisanu, A.; Lazar, I.G.; Pop, M.D.; Ungureanu, E.-M.; Isopescu, R.; Birzan, L. Polyazulenes Based Materials for Heavy Metal Ions Detection. Rev. Chim. 2017, 68, 2215-2218. [CrossRef]

30. Dias, J.R. Electronic and structural properties of biazulene, terazulene, and polyazulene isomers. J. Phys. Org. Chem. 2007, 20, 395-409. [CrossRef]

31. Huang, J.; Huang, S.; Zhao, Y.; Feng, B.; Jiang, K.; Sun, S.; Ke, C.; Kymakis, E.; Zhuang, X. Azulene-Based Molecules, Polymers, and Frameworks for Optoelectronic and Energy Applications. Small Methods (Adv. Sci. News) 2020, 4, 2000628. [CrossRef]

32. Sun, Q.; Hou, I.C.-Y.; Eimre, K.; Pignedoli, C.A.; Ruffieux, P.; Narita, A.; Fasel, R. On-surface synthesis of polyazulene with 2,6-connectivity. Chem. Commun. 2019, 55, 13466-13469. [CrossRef]

33. Fan, Q.; Martin-Jimenez, D.; Ebeling, D.; Krug, C.K.; Brechmann, L.; Kohlmeyer, C.; Hilt, G.; Hieringer, W.; Schirmeisen, A.; Gottfried, J.M. Nanoribbons with Nonalternant Topology from Fusion of Polyazulene: Carbon Allotropes beyond Graphene. J. Am. Chem. Soc. 2019, 141, 17713-17720. [CrossRef] [PubMed]

34. Shoji, T.; Okujima, T.; Ito, S. Development of Heterocycle-Substituted and Fused Azulenes in the Last Decade (2010-2020). Int. J. Mol. Sci. 2020, 21, 7087. [CrossRef] [PubMed]

35. Fujimura, M.; Nakazawa, T.; Murata, I. A novel coupling reactiong of 1-azylylmethyltrimethylammonium iodide. Synthesis of 1,2-bis[1-azulyl)ethane and [2.2.2.2](1,3)azulenophane. Tetrahedron Lett. 1979, 20, 825-828. [CrossRef]

36. Razus, A.C. Azulene Moiety as Electron Reservoir in Positively Charged Systems; A Short Survey. Symmetry 2021, $13,526$. [CrossRef]

37. Stepanov, F.N.; Yurchenko, A.G. Condensation of Azulenes with Carboxylic Acid Anhydrides. Zh. Obshch. Khim. 1964, 34, 894-899.

38. Hünig, S.; Ort, B. Mehrstufige reversible Redoxsysteme, XXXVII. Biazulenyle und $\omega, \omega^{\prime}$-Biazulenylpolyene: Synthesen und spektroskopische Eigenschaften. Liebigs Ann. Chem. 1984, 12, 1905-1935. [CrossRef]

39. Razus, A.C.; Dragu, E.A.; Nica, S.; Nicolescu, A. Reductive coupling of (azulen-1-yl)carbonyl compounds by low-valent titanium; pinacol/pinacolone rearrangement versus pinacol and alkene generation. Tetrahedron Lett. 2011, 52, 1858-1862. [CrossRef]

40. Dragu, E.A.; Nica, S.; Raicopol, M.; Baran, A.; Anghel, D.-F.; Cojocaru, B.; Tarko, L.; Razus, A.C. Synthesis, solid-state photophysical properties and electropolymerization of novel diazulenyl ethenes. Tetrahedron Lett. 2012, 53, 2611-2614. [CrossRef]

41. Dragu, E.A.; Razus, A.C. Ring size effect in McMurry cyclization of 1,w-di((azulen-1-yl)-carbonyl) alkanes. Rev. Roum. Chim. 2020, 65, 83-88. [CrossRef]

42. Shoji, T.; Araki, T.; Iida, N.; Kobayashi, Y.; Ohta, A.; Sekiguchi, R.; Ito, S.; Mori, S.; Okujima, T.; Yasunami, M. Molecular Transformation of 2-Methylazulenes: An Efficient and Practical Synthesis of 2-Formyl- and 2-Ethynylazulenes. Eur. J. Org. Chem. 2018, 9, 1145-1157. [CrossRef]

43. Razus, A.C.; Nitu, C.; Tecuceanu, V.; Cimpeanu, V. 2-Substituted (Azulen-1-yl)ethenes. Eur. J. Org. Chem. 2003, 23, 4601-4610. [CrossRef]

44. Shoji, T.; Araki, T.; Iida, N.; Miura, K.; Ohta, A.; Sekiguchi, R.; Ito, S.; Okujima, T. Synthesis of azulenophthalimides by phosphine-mediated annulation of 1,2-diformylazulenes with maleimides. Org. Chem. Front. 2019, 6, 195-204. [CrossRef]

45. Kurotobi, K.; Tabata, H.; Miyauchi, M.; Murafuji, T.; Sugihara, Y. Coupling Reaction of Azulenyl-4,4,5,5-tetramethyl-1,3,2dioxaborolanes with Haloazulenes. Synthesis 2002, 8, 1013-1016. [CrossRef]

46. Xin, H.; Gao, X. Application of Azulene in Constructing Organic Optoelectronic Materials: New Tricks for an Old Dog ChemPlusChem 2017, 82, 945-956. [CrossRef] [PubMed]

47. Matano, Y.; Kon, Y.; Saito, A.; Kimura, Y.; Murafuji, T.; Imahori, H. Divergent Synthesis of 2,5-Diarylphospholes Based on Cross-coupling Reactions: Substituent Effects on the Optical and Redox Properties of Benzene-Phosphole-Benzene $\pi$-Systems. Chem. Lett. 2011, 40, 919-921. [CrossRef]

48. Shoji, T.; Maruyama, A.; Araki, T.; Ito, S.; Okujima, T. Synthesis of 2- and 6-thienylazulenes by palladium-catalyzed direct arylation of 2- and 6-haloazulenes with thiophene derivatives. Org. Biomol. Chem. 2015, 13, 10191-10197. [CrossRef] [PubMed]

49. Yamaguchi, Y.; Maruya, Y.; Katagiri, H.; Nakayama, K.-I.; Ohba, Y. Synthesis, Properties, and OFET Characteristics of 5,5'-Di(2azulenyl)-2,2'-bithiophene (DAzBT) and 2,5-Di(2-azulenyl)-thieno[3,2-b]thiophene (DAzTT). Org. Lett. 2012, 14, $2316-2319$. [CrossRef] [PubMed]

50. Poronik, Y.M.; Mazur, L.M.; Samo'c, M.; Jacquemin, D.; Gryko, D.T. 2,5-Bis(azulenyl)pyrrolo[3,2-b]pyrroles-The key influence of the linkage position on the linear and nonlinear optical properties. J. Mater. Chem. C 2017, 5, 2620-2628. [CrossRef]

51. Razus, A.C.; Birzan, L. Synthesis of azulenic compounds with a homo- or hetero-atomic double bond at position 1 . Arkivoc 2018, IV, 1-56. [CrossRef]

52. Löhr, H.G.; Vögtle, F.; Schuh, W.; Puff, H. Chromoionophore mit Azulen-Einheiten als Farbträger und $\pi$-Donor-Baustein. Chem. Ber. 1984, 117, 2839-2849. [CrossRef]

53. Birzan, L.; Tecuceanu, V.; Cristea, M.; Draghici, C.C.; Hanganu, A.; Razus, A.C. New Benzo- and Dibenzo-Crown Ethers with (Azulen-1-yl)Vinyl Substituents. Rev. Chim. 2020, 71, 1-9. [CrossRef]

54. Razus, A.C.; Birzan, L.; Tecuceanu, V.; Cristea, M.; Hanganu, A. Benzo- and dibenzo-crown ethers substituted with (azulene-1-yl) azo chromophores. Synthesis and properties. Rev. Roum. Chim. 2012, 57, 987-995. 
55. Shetti, V.S. Chemical syntheses and salient features of azulene-containing homo- and copolymers. Beilstein J. Org. Chem. 2021, 17, 2164-2185. [CrossRef] [PubMed]

56. Wang, F.; Lai, Y.-H.; Han, M.Y. Post-Coordination of Multinuclear Transitional Metal Clusters to Azulene-Based Polymers: A Novel Strategy for Tuning Properties in $\pi$-Conjugated Polymers. Org. Lett. 2003, 5, 4791-4794. [CrossRef] [PubMed]

57. Murai, M.; Amir, E.; Amir, R.J.; Hawker, C.J. Azulene-based conjugated polymers: Unique seven-membered ring connectivity leading to stimuli-responsiveness. Chem. Sci. 2012, 3, 2721-2725. [CrossRef]

58. Hou, I.C.-Y.; Shetti, V.; Huang, S.-L.; Liu, K.-L.; Chao, C.-Y.; Lin, S.-C.; Lin, Y.-J.; Chen, L.-Y.; Luh, T.-Y. Poly[2(6)-aminoazulene]: Synthesis, photophysical properties, and proton conductivity. Org. Chem. Front. 2017, 4, 773-778. [CrossRef]

59. Lete, C.; Esteban, B.M.; Kvarnström, C.; Razus, A.C.; Ivaska, A. Electrosynthesis and characterization of poly(2-[(E)-2-azulen-1ylvinyl] thiophene) using polyazulene as model compound. Electrochimica Acta 2007, 52, 6476-6483. [CrossRef]

60. Luhowy, R.; Keehn, P.M. Cyclophanes V. anti-[2.2] (2,6) azulenophane. Tetrahedron Lett. 1976, 17, 1043-1046. [CrossRef]

61. Kato, N.; Fukazawa, Y.; Itô, S. Synthesis of anti-[2,2] $(2,6)$ azulenophane from 5-methyltropolone. Tetrahedron Lett. 1976, 17, 2045-2048. [CrossRef]

62. Georghiou, P.E.; Rahman, S.; Alodhayb, A.; Nishimura, H.; Lee, J.; Wakamiya, A.; Scott, L.T. Calixazulenes: Azulene-based calixarene analogues-An overview and recent supramolecular complexation studies. Beilstein J. Org. Chem. 2018, 14, 2488-2494. [CrossRef]

63. Georghiou, P.E.; Schneider, C.; Shamov, G.; Lash, T.D.; Rahman, S.; Giddings, D.S. Mechanochemical formation of a 1:1 C60: Tert-butylcalix[4]azulene supramolecular complex: Solid-state NMR and DFT computational studies. Supramol. Chem. 2016, 28, 396-402. [CrossRef]

64. Asao, T.; Ito, S.; Morita, N. Synthesis of [1.1.1.1] (1,3)-2-methoxyazulenophane: Azulene analogue of calixarenes. Tetrahedron Lett. 1988, 29, 2839-2842. [CrossRef]

65. Colby, D.A.; Lash, T.D. Calix[4]azulene. J. Org. Chem. 2002, 67, 1031-1033. [CrossRef] [PubMed]

66. Lash, T.D.; El-Beck, J.A.; Colby, D.A. Synthesis of a Tetraazulene Porphodimethene Analogue. J. Org. Chem. 2009, 74, 8830-8833. [CrossRef] [PubMed]

67. Shoji, T.; Higashi, J.; Ito, S.; Toyota, K.; Iwamoto, T.; Morita, N. Synthesis and Properties of Ferrocenylmethylene-Bridged Calix[4]azulene and a New Example of Bis(1-azulenyl)ferrocenylmethylium Ion. Eur. J. Org. Chem. 2009, 34, 5948-5952. [CrossRef]

68. Sprutta, N.; Maćkowiak, S.; Kocik, M.; Szterenberg, L.; Lis, T.; Latos-Grażyński, L. Tetraazuliporphyrin Tetracation. Angew. Chem. Int. Ed. Engl. 2009, 48, 3337-3341. [CrossRef]

69. Kurotobi, K.; Kim, K.S.; Noh, S.B.; Kim, D.; Osuka, A. A Quadruply Azulene-Fused Porphyrin with Intense Near-IR Absorption and a Large Two-Photon Absorption Cross Section. Angew. Chem. Int. Ed. Engl. 2006, 45, 3944-3947. [CrossRef]

70. Kurotobi, K.; Osuka, A. Synthesis of meso-Azulenylporphyrins. Org. Lett. 2005, 7, 1055-1058. [CrossRef]

71. Zhang, Z.; Ferrence, G.M.; Lash, T.D. adj-Diazuliporphyrins, a New Family of Dicarbaporphyrinoids with Unprecedented Mesoionic Characteristics. Org. Lett. 2009, 11, 101-104. [CrossRef]

72. Lash, T.D. Out of the Blue! Azuliporphyrins and Related Carbaporphyrinoid Systems. Accounts Chem. Res. 2016, 49, 471-482. [CrossRef]

73. Sprutta, N.; Świderska, M.; Latos-Grażyński, L. Dithiadiazuliporphyrin: Facile Generation of Carbaporphyrinoid Cation Radical and Dication. J. Am. Chem. Soc. 2005, 127, 13108-13109. [CrossRef] [PubMed]

74. Sprutta, N.; Siczek, M.; Latos-Grażyński, L.; Pawlicki, M.; Szterenberg, A.L.; Lis, T. Dioxadiazuliporphyrin: A Near-IR Redox Switchable Chromophore. J. Org. Chem. 2007, 72, 9501-9509. [CrossRef] [PubMed] 